\title{
Transition of lodine Analysis to Accelerator Mass Spectrometry
}

IN13-AMS255-3TE

M. L. Adamic

D. L. Baeck, Ph.D.

J. G. Eisenmenger

R. V. Fox, Ph.D.

P. A. Hahn

D.D. Jenson, Ph.D.

T. E. Lister, Ph.D.

J. E. Olson

M. G. Watrous, Ph.D., Principal Investigator

September 2015

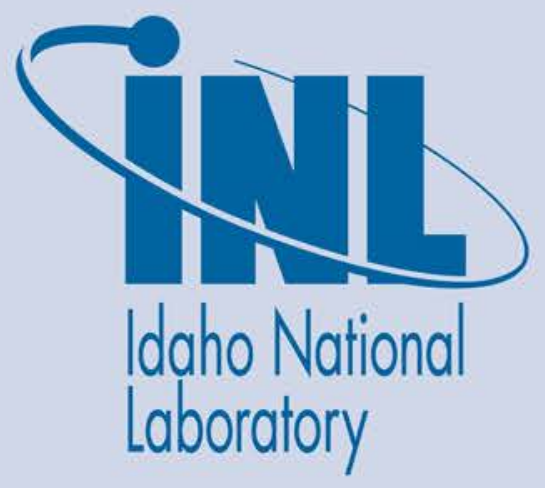

\author{
Prepared for the \\ U.S. Department of Energy \\ Office of DNN R\&D \\ Under DOE Idaho Operations Office \\ Contract DE-AC07-05ID14517
}

The INL is a U.S. Department of Energy National Laboratory operated by Battelle Energy Alliance 


\section{DISCLAIMER}

This information was prepared as an account of work sponsored by an agency of the U.S. Government. Neither the U.S. Government nor any agency thereof, nor any of their employees, makes any warranty, expressed or implied, or assumes any legal liability or responsibility for the accuracy, completeness, or usefulness, of any information, apparatus, product, or process disclosed, or represents that its use would not infringe privately owned rights. References herein to any specific commercial product, process, or service by trade name, trade mark, manufacturer, or otherwise, does not necessarily constitute or imply its endorsement, recommendation, or favoring by the U.S. Government or any agency thereof. The views and opinions of authors expressed herein do not necessarily state or reflect those of the U.S. Government or any agency thereof. 


\section{EXECUTIVE SUMMARY}

The goal of the project, New Paradigms for Isotope Ratio Mass Spectrometry: Raising the Scientific Profile and Improved Performance for Accelerator Mass Spectrometry (AMS) and Thermal Ionization Mass Spectrometry (TIMS), is to ensure the ongoing isotope ratio determination capability within the U.S. Department of Energy complex is world class for application to nonproliferation. This report spells out the progress of Task 4, Transition of TIMS to AMS for Iodine Analysis, of the larger project. The subtasks under Task 4 and the accomplishments throughout the three year project life cycle are presented in this report. Progress was made in optimization of chemical extraction, determination of a detection limit for ${ }^{127}$ Iodine, production of standard materials for AMS analysis quality assurance, facilitation of knowledge exchange with respect to analyzing iodine on an AMS, cross comparison with a world leading AMS laboratory, supercritical fluid extraction of iodine for AMS analysis and electrodeposition of seawater as a direct method of preparation for iodine analysis by AMS. All with the goal of minimizing the time required to stand up an AMS capability for iodine analysis of exposed air filters at INL.

An effective extraction method has been developed and demonstrated for iodine analysis of exposed air filters. Innovative techniques to accomplish the cathode preparation for AMS analysis were developed, demonstrated and published. The known lack of available materials for reference standards in the analysis of iodine by AMS was filled by the preparation of homogenous materials that were calibrated against NIST materials. A minimum detection limit on the amount of abundant isotope in a sample was determined for AMS analysis. The knowledge exchange occurred with fantastic success. Scientists engaged the international AMS community at conferences, as well as in their laboratories for collaborative work. The supercritical fluid extraction work has positive data, but is not a replacement for leaching. The added seawater work has led to a new method and a possible publication.

The focus of this project was to minimize the time to stand up the AMS capability, by having all the preparation and supporting functions worked out ahead of the instrument arrival. Due to all the preparatory work and its success, the instrument was delivered and turned over to the INL in February 2015. Since then, INL scientists have been successfully vetting the capabilities and accomplishing their own iodine measurements that agree well with the leading AMS laboratories of the world. To transition INL mass spectroscopy scientists to AMS operation, early AMS data was gathered at a collaborative laboratory on their instrument, but during the last six months data for this project has come from INL's AMS. 


\section{ACRONYMS}

AMS Accelerator Mass Spectrometry

ETH Eidgenössische Technische Hochschule (Swiss Federal Institute of Technology in Zurich)

FY fiscal year

INL Idaho National Laboratory

IPA isopropyl alcohol

NIST National Institute of Standards and Technology

TIMS thermal ionization mass spectrometry

TMAH tetramethyl ammonium hydroxide 


\section{Transition of lodine Analysis to Accelerator Mass Spectrometry}

\section{INTRODUCTION}

The focus of the New Paradigms for Isotope Ratio Mass Spectrometry: Raising the Scientific Profile and Improved Performance for AMS and TIMS program is development of new instrumental methodologies that are designed to improve measurement throughput and analytical performance, including higher abundance sensitivity, shorter analysis time, reduced instrument and operational costs, and a much-expanded range of potential isotopic signatures. These objectives are ambitious; however, it is likely that significantly improved isotope ratio mass spectrometry performance is on the relatively close horizon as a result of recent advances in mass spectrometry.

Iodine samples typically have been analyzed at Idaho National Laboratory (INL) for isotopic content $\left({ }^{127}\right.$ I, $\left.{ }^{129} \mathrm{I}\right)$ using thermal ionization mass spectrometry (TIMS). The environmental samples traditionally have been collected on charcoal filters, which have been processed by gas-phase chemistry, yielding an aqueous solution for analysis on a triple-sector mass spectrometer. A good year afforded the analysis of 120 samples, along with the appropriate quality control samples. A batch of 20 samples, plus six samples for quality control, requires about 1 month for chemical processing, plus 1 month for the instrumental analysis, data review, and reporting. There has long been a desire to increase the throughput of iodine isotopic determinations.

Accelerator mass spectrometry (AMS) has the potential to facilitate a large step forward in iodine analyses. Not only is the instrumental time per sample analysis reduced for AMS, the required chemical purification is less stringent. This greatly simplifies the chemical processing portion of the work by about a factor of eight. An added benefit, the AMS instrumental background levels are much lower, allowing lower detection limits $\left({ }^{129} \mathrm{I} /{ }^{127} \mathrm{I}\right.$ ratio) by three orders of magnitude.

Iodine measurement research focused on increased sample handling efficiencies, improved techniques for iodine extraction and cathode fabrication. The current approaches to iodide analysis are functional, but are operationally complex and labor intensive, which contribute to the overall difficulty, time, and expense of sample analysis. The transition of iodine analysis from TIMS to AMS program developed sample handling methodologies that will reduce sample handling complexity and cost per sample and, at the same time, increase analytical throughput and abundance sensitivity. Improved sample processing techniques, combined with the increased sample throughput of an AMS for iodine, are expected to generate analysis rates that are an order of magnitude higher than those achievable using TIMS.

The objective of this task is to capitalize on the recent purchase of a 0.5 -million volt AMS, with delivery to INL in December of 2014. A U.S. government client purchased the instrument, based on the success of a previous NA22 project (IN10-IAnalysis-PD08-FY10). INL researchers had successfully demonstrated that the data produced by AMS analysis were comparable to TIMS results for the same set of air filters. The iodine extraction and purification methods were improved with limited project funding in Fiscal Years (FY) 2010 and 2012. Significant improvements were made in FY 2013; INL furthered its work for preparation of AMS cathodes containing the silver iodide matrix and gained hands-on operating experience with a 0.5 -MV AMS running samples prepared at INL. All of these accomplishments have reduced the time to begin successful iodine analyses on the new AMS at INL and reduced the time between acceptance of the AMS and the INL methods and staff becoming "fully mission capable," meaning routine production of valuable data at increased production rates. 


\section{BACKGROUND}

At present, the highest abundance sensitivity isotope ratio measurements are carried out using AMS, which has enabled truly remarkable achievements in the measurement of vanishingly small percentages of minor isotopes in the presence of overwhelming percentages of the naturally occurring isotopes. For example, recent research has demonstrated AMS measurement of iodine isotope ratios at levels equivalent to the best levels achievable using TIMS. This result was intriguing because the sample throughput and analytical performance using the AMS methodology have the potential to be significantly better than that achievable using TIMS. These and other studies sparked interest in increasing both the numbers and types of measurements using AMS; however, the technique has inherent limitations in terms of sample preparation and instrumental complexity. In order to take advantage of the obvious power of AMS, better methodologies and instrumental approaches are needed for high-abundance sensitivity isotope ratio measurements.

Traditionally, iodine measurements by AMS have been conducted on larger instruments operating at terminal voltages as high as $30 \mathrm{MV}$ and utilizing the +5 charge state of iodine. Researchers at ETH in Zurich, using a $0.5-\mathrm{MV}$ instrument, have demonstrated the use of silicon nitride windows in the detectors, allowing the use of the +3 charge state. Detection studies have been further extended to the +2 charge state with marked success, making the compact AMS very comparable to larger instruments for instrument blank levels and transmission through the accelerator. The lower charge states are more highly-populated than the higher ones, which facilitates lower detection limits via better sample utilization.

The ${ }^{129} \mathrm{I} /{ }^{127} \mathrm{I}$ ratio in the environment is used in nuclear nonproliferation forensic activities. Anthropogenic sources of ${ }^{129} \mathrm{I}$ in the surface environment are from above-ground testing of nuclear weapons, nuclear fuel reprocessing, and events such as Chernobyl and Fukushima. ${ }^{129}$ I can be used for multiple applications in environmental studies, ranging from oceanography, to radioecology, and to age dating of materials. The breadth of applications is well addressed in the literature, which contains dozens of reports of AMS analysis of ${ }^{129} \mathrm{I}$ over the past few years. The relative abundance of ${ }^{129} \mathrm{I}$ in relation to the naturally occurring and much more abundant ${ }^{127} \mathrm{I}$ makes AMS the most fitting tool for analysis. Modern ${ }^{129} \mathrm{I} /{ }^{127} \mathrm{I}$ ratios range from about $1 \times 10^{-6}$ for effluents from fuel reprocessing ${ }^{1}$, to $1 \times 10^{-9}$ for Baltic Sea water, to 1 $\mathrm{x} 10^{-14}$ for brine wells. Variations in ${ }^{129} \mathrm{I} /{ }^{127} \mathrm{I}$ values are due to anthropogenic sources mixing with naturally occurring iodine.

Historically, ${ }^{129}$ I has been measured using TIMS; however, there are two compelling reasons that favor AMS. First, AMS is far more robust as an analytical method compared to TIMS and it requires significantly less sample purification prior to analysis. Second, AMS has a much wider dynamic range that enables measurement of much lower ${ }^{129} \mathrm{I} /{ }^{127} \mathrm{I}$ ratios. The destruction of molecular interferences occurring inside the AMS terminal reduces the required sample preparation and decreases measurement time on the instrument. As a result, more analyses can be performed for the same amount of labor expense. The increased sensitivity of AMS is 1,000 times better than the present INL TIMS capability $\left(10^{-13}\right.$ vs $10^{-10}$.) This will allow an evaluation of the global environmental background and will enable routine measurement of ratios orders of magnitude below the current instrumental baseline. This improved capability will allow answers to questions such as: Is the TIMS baseline the environmental background or the detection limit of the TIMS instrument? Is there more information to be harvested below the present levels of detection?

The capacity of a fully functional, compact AMS is 35 to 80 samples per day, depending on adequate pumping capability between sample loads. This leads to sample preparation chemistry as the rate-limiting step in the processing of iodine samples. The present process of gas purification used for TIMS requires ${ }^{1}$ H.Wershofen, and D.C. Aumann, Iodine-129 in the environment of a nuclear fuel reprocessing plant: VII. Concentrations and
chemical forms of ${ }^{129}$ I and ${ }^{127}$ I in the atmosphere. J. Environ. Radioact. 10 (1989) 141. 
three weeks to process 20 samples. The large time investment required is due to the necessity of the extreme chemical purity needed for TIMS samples.

Five activities related to iodine analysis using a 0.5-MV AMS were proposed to decrease the time between instrument arrival and commencement of productive sample analysis and to improve overall expertise levels. First, the extraction technique developed in Project IN10-IAnalysis-PD08-FY12 was refined through the process step of cathode production and analysis on a 0.5-MV AMS, which demonstrated sample integrity and no cross contamination. Second, the detection limit of ${ }^{127}$ I was demonstrated for electrodeposition $(10 \mu \mathrm{g})$ to allow the determination of sample collection media options that fall within the range of an AMS ( $1 \times 10^{-11}-1 \times 10^{-10}{ }^{129} \mathrm{I} /{ }^{127} \mathrm{I}$ ratios $)$. Third, a standard matrix material was developed and characterized for use at INL. Fourth, education of the INL staff was enhanced by working side by side in an AMS laboratory and interacting with experts in the field of AMS analysis. Lastly, AMS analysis at INL was cross compared with a world leading AMS laboratory at ETH-Zurich. Two additional sub tasks were added over the execution of the project, the further exploration of supercritical fluid extraction and the direct electrochemical processing of sea water. 


\section{WORK PERFORMED AT IDAHO NATIONAL LABORATORY}

\subsection{Task 4.1 Filter Extraction Optimization for Efficient Sample Processing}

To be inclusive of new ideas and broaden the considered approaches to sample preparation, the project kicked off with a brainstorming session. A collaborative brainstorming session to frame and guide extraction optimization was held, with multiple national laboratories and private industry participating. The guidance coming from the team was to pursue a leaching process and capitalize on the collection of iodine directly onto the silver sample introduced into the AMS. With the potential of simpler sample preparation, supercritical fluid extraction was pursued in parallel to the liquid extraction. This work is reported separately in Task 4.1 extension (following this section). The leach method has been successful and the development into a complete sample preparation protocol is described here.

\subsubsection{Collaborative Brainstorming}

INL held a brainstorming session to guide the work in developing and streamlining the extraction of iodine from high-volume air filters. Before the session, work had already begun on an extraction method that used liquid extraction of a filter, followed by classical liquid/liquid extraction chemistry to clean up the iodine fraction, which was followed by precipitation of a silver iodide solid that is pressed into the cathode. The goal of the session was to determine if there was another technique or alteration to the proposed technique that would provide the desired iodine extracted from the high-volume air filter more cleanly or quickly. Attendees from across INL, Pacific Northwest National Laboratory, and industry came together. One outcome of the brainstorming session was to determine that a leach process, similar to the one that had been developed thus far, was a good idea. Electrodeposition was suggested to overcome the hurdle that has made it difficult to take the iodine from the tetramethyl ammonium hydroxide (TMAH) extract to silver iodide. An additional outcome of the brainstorming was to evaluate supercritical fluid extraction (SFE) from the high-volume air filters. SFE was expected to produce a much cleaner extract already in an organic solvent for trapping on silver through already proven techniques. Trapping iodine in copper wool or silver zeolite for use in AMS cathode preparation was also suggested during the brainstorming session. Microwave digestion, accelerated solvent extraction, cryogenic fracturing of the air filter, ultrasonic aid to the liquid extraction, and a catalytic oxidation for removal of iodine from the air filter were all suggested as techniques to explore in improving current systems.

\subsubsection{Extraction Development}

A survey of the literature indicated that TMAH is routinely used for the extraction of iodine from environmental matrices (soil, vegetation, air samples). ${ }^{2,3}$ Using TMAH has three major advantages, it has a low ICP-MS blank for ${ }^{127} \mathrm{I}$, standards and samples are stable for months, and the extraction requires mild conditions. INL evaluated a number of different extraction methods; microwave digestion, Parr vessels in a heated oven and a heated ultrasonic bath. All of these methods resulted in the extraction of the iodine species from soil/sediment standards. The data obtained from the extraction of various NIST/IAEA standards is summarized in Table 1. Ten aliquots of each standard was prepared by leaching in $5 \%$ TMAH heated to $90{ }^{\circ} \mathrm{C}$ for approximately 10 hours and analyzed by ICP-MS. The data obtained for total iodine compared favorably with the certified or consensus values for the standards.

\footnotetext{
${ }^{2}$ H. Yamada, T. Kiriyama,., and K. Yonebayashi. Determination of total iodine in soils by inductively coupled plasma mass spectrometry, Soil Sci. Plan Nutr. 42 (1996) 859.

3 J. A. Nóbrega, M. C. Santos, R. A. de Sousa, S. Cadore, R. M. Barnes, and M. Tatro Sample preparation in alkaline media, Spectrochimica Acta Part B 61 (2006) 465.
} 


\begin{tabular}{|c|c|c|c|}
\hline Standard ID & $\begin{array}{c}\sim \text { Iodine } \\
\text { concentration } \\
(\boldsymbol{\mu g} \text { I/g standard) }\end{array}$ & $\begin{array}{c}\text { Sample mass } \\
\text { (grams) }\end{array}$ & $\begin{array}{c}\text { \% Recovery } \\
\text { (ICP-MS data) }\end{array}$ \\
\hline $\begin{array}{c}\text { IAEA-375 } \\
\text { Chernobyl soil }\end{array}$ & 1.44 & 0.25 & 113 \\
\hline $\begin{array}{c}\text { NIST-2710 } \\
\text { Montana Soil }\end{array}$ & $\sim 3$ & 0.25 & 119 \\
\hline $\begin{array}{c}\text { NBS-1572 } \\
\text { Citrus Leaves }\end{array}$ & 1.44 & 0.25 & 89 \\
\hline PNNL Maple Leaves & 1.4 & 0.25 & 83 \\
\hline
\end{tabular}

Table 1. Results of ICP-MS analyses of environmental soil materials after leaching with TMAH In addition, IAEA-375 and NIST-4354 (after addition of carrier) were analyzed by AMS at ETH, the data is summarized in Table 2. The data agrees favorably with the IAEA-375 certificate value for ${ }^{129} \mathrm{I}$ and the value reported in the literature for NIST-4354 ${ }^{4}$.

\begin{tabular}{|c|c|c|c|c|}
\hline Standard ID & $\begin{array}{c}\sim \text { Iodine } \\
\text { concentration } \\
(\boldsymbol{\mu g} \mathbf{I} / \mathbf{g} \text { standard) }\end{array}$ & $\begin{array}{c}\text { Sample mass } \\
(\mathbf{g r a m s})\end{array}$ & $\begin{array}{c}\mathbf{I - 1 2 9} \\
(\mathrm{Bq} / \mathrm{kg})\end{array}$ & $\begin{array}{c}\text { INL } \\
\text { Analysis } \mathbf{~}(\mathbf{B q} / \mathbf{k g})\end{array}$ \\
\hline $\begin{array}{c}\text { IAEA-375 } \\
\text { Chernobyl soil }\end{array}$ & 1.44 & 1 & $0.0017 \pm 0.0004^{\mathrm{a}}$ & $0.0017 \pm 0.00027$ \\
\hline $\begin{array}{c}\text { IAEA-375 } \\
\text { Chernobyl soil }\end{array}$ & 1.44 & 5 & $0.0017 \pm 0.0004^{\mathrm{a}}$ & $0.0017 \pm 0.00026$ \\
\hline $\begin{array}{c}\text { NIST-4354 } \\
\text { Lake Sediment }\end{array}$ & 7 & 1 & $0.044 \pm 0.006^{\mathrm{b}}$ & $0.047 \pm 0.0068$ \\
\hline
\end{tabular}

${ }^{\mathrm{a}}$ IAEA-375 certificate, ${ }^{\mathrm{b}}$ Ref. [4]. ${ }^{\mathrm{c}}$ No correction for losses in processing was made.

Table 2. Results of AMS analyses of environmental soil materials

INL personnel chose to use a heated ultrasonic bath as it is the simplest method and requires the least expensive consumables. In addition, the number of samples that can be prepared at one time is not limited due to the capacity of a microwave or oven.

\footnotetext{
${ }^{4}$ J. Qiao, V. Hansen, X. Hou, A. Aldahan, G. Possnert, Speciation analysis of ${ }^{129} I,{ }^{137} \mathrm{Cs},{ }^{232} \mathrm{Th},{ }^{238} U{ }^{239} \mathrm{Pu}$ and ${ }^{240} \mathrm{Pu}$ in environmental soil and sediment, Appl.Radiat. Isot. 70 (2012) 1698.
} 
The aqueous extraction method for filter media, as presently defined, makes use of a leaching process in isopropyl alcohol (IPA) $+5 \%$ TMAH overnight in a $90{ }^{\circ} \mathrm{C}$ water ultrasonic bath. After cooling, the leachates are decanted or centrifuged for separation of remaining solids. A dilution (usually a 1:10) is made of each leachate and the ${ }^{127}$ I concentration determined by ICP-MS.

\subsubsection{Analysis of ${ }^{127}$ I by ICP-MS}

The analysis of ${ }^{127} \mathrm{I}$ in the leachate is accomplished using a Thermo Scientific iCAP Q ICP-MS with an Elemental Scientific SC-2 DX autosampler and prepFAST (automated sample preparation), see

Photograph 1. Initially, the sample leachates are screened at a dilution of 1:10,000. Based on the screen results, the leachates are diluted at the appropriate level for analysis. The instrument collects 7 scans at masses 72 (internal standard used is germanium) and 127. An initial calibration is analyzed using 6 levels of a certified standard ranging from $0.5 \mathrm{ppb}$ to $40 \mathrm{ppb}$. A verification standard (a standard prepared from a certified secondary source) is analyzed intermittently (between 6 samples) during the analysis to confirm that the initial calibration is still accurate. Instrument blanks are analyzed along with the verification standard to confirm the absence of ${ }^{127}$ I carryover between sample analyses. The instrument has an automated sample preparation device that adds $10 \mathrm{ppb}$ of germanium to every injection. The instrument uses the response of the germanium at mass 72 to normalize the response at mass 127 . The concentration of the sample is calculated using linear regression. Samples are analyzed in duplicate to confirm the absence of data anomalies. The average result is reported as the concentration of ${ }^{127} \mathrm{I}$ in the sample leachate.

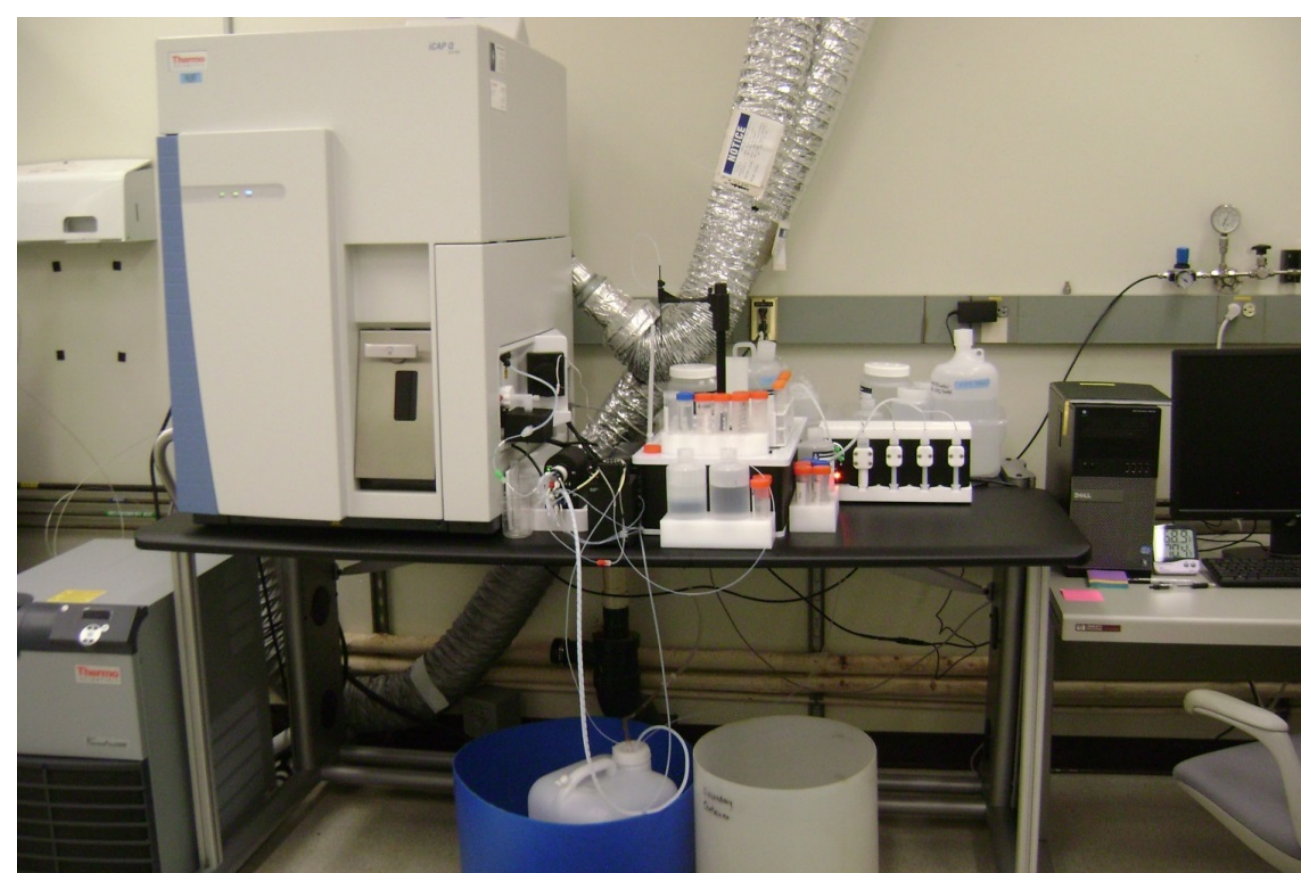

Photograph 1. Thermo Scientific iCAP Q ICP-MS 


\subsubsection{Addition of Carrier}

Once the ${ }^{127} \mathrm{I}$ is quantified, an aliquot of the sample leachate is removed and carrier ${ }^{127} \mathrm{I}$ is added $\left({ }^{129} \mathrm{I} /{ }^{127} \mathrm{I}\right.$ ratio of $\sim 5 \times 10^{-13}$, Inorganic Ventures ion chromatography standard certified for concentration). This is followed by oxidation reduction chemistry steps to ensure isotopic equilibration of the carrier and sample iodine $^{5}$. Table 3 summarizes the recovery of $1000 \mu \mathrm{g}$ of iodide added to $4 \mathrm{~mL}$ of $5 \%$ TMAH through the oxidation reduction chemistry. The average recovery is $97 \%$.

\begin{tabular}{|c|c|}
\hline Sample ID & \% recovery \\
\hline 1 & $93.8 \%$ \\
\hline 2 & $94.5 \%$ \\
\hline 3 & $97.2 \%$ \\
\hline 4 & $98.5 \%$ \\
\hline 5 & $99.8 \%$ \\
\hline
\end{tabular}

Table 3. Recovery of $1000 \mu \mathrm{g}$ of iodide from $5 \% \mathrm{TMAH}$

Five aliquots of NIST $32311 \times 10^{-8}$ standard were diluted to the $1 \times 10^{-11}$ range for the ${ }^{127} \mathrm{I} /{ }^{129}$ I ratio with pure ${ }^{127} \mathrm{I}$. One of the samples, \#2 was prepared via electrodeposition in triplicate. The samples were analyzed by AMS at ETH. The data obtained is summarized in Table 4, shows a consistent preparation of a sample from the $1 \times 10^{-8}{ }^{129} \mathrm{I} /{ }^{127} \mathrm{I}$ range down to the $10^{-11}{ }^{129} \mathrm{I} /{ }^{127} \mathrm{I}$ range. This is anticipated to be a method of running environmental samples to prevent the introduction of too much ${ }^{129}$ I into the AMS system. Samples will be prepared with a conservative dilution and then adjusted to be in the right range for the instrument performance and standards available.

\begin{tabular}{|c|c|}
\hline Sample \# & Measured ${ }^{\mathbf{1 2 9}} \mathbf{I}{ }^{\mathbf{1 2 7}} \mathbf{I}$ ratio $\left(\mathbf{1} \times \mathbf{1 0}^{\mathbf{- 1 1}}\right)$ \\
\hline$\# 1$ & $5.25 \pm 0.04$ \\
\hline$\# 2-1$ & $5.29 \pm 0.05$ \\
\hline$\# 2-2$ & $5.28 \pm 0.05$ \\
\hline$\# 2-3$ & $5.35 \pm 0.05$ \\
\hline$\# 3$ & $5.31 \pm 0.05$ \\
\hline$\# 4$ & $5.19 \pm 0.05$ \\
\hline$\# 5$ & $5.09 \pm 0.03$ \\
\hline
\end{tabular}

Table 4. Data as generated via AMS analysis, on NIST $32311 \times 10^{-8}{ }^{129} \mathrm{I} /{ }^{127} \mathrm{I}$ standard solution. These data show raw data from the instrument, which includes the added carrier. Thus the measured ratio is indicative of the diluted NIST standard, showing precision of the data.

Plot 1 takes the data from Table 4 and calculates the ${ }^{129} \mathrm{I} /{ }^{127} \mathrm{I}$ ratio in the initial sample. This was the $1 \mathrm{x}$ $10^{-8}{ }^{129} \mathrm{I} /{ }^{127} \mathrm{I}$ standard with an average measured value very close to the certified value. All measurements and the certified value are within 2-sigma uncertainty bounds of each other. This demonstrates successfully diluting a sample, making the AMS measurement and calculating the value of the original sample correctly.

\footnotetext{
${ }^{5}$ Comprehensive Handbook of Iodine: Nutritional, Biochemical, Pathological and Therapeutic Aspects, edited by V. R. Preedy, G. N. Burrow, R. R. Watson, (2009) 175.
} 
NIST E-8

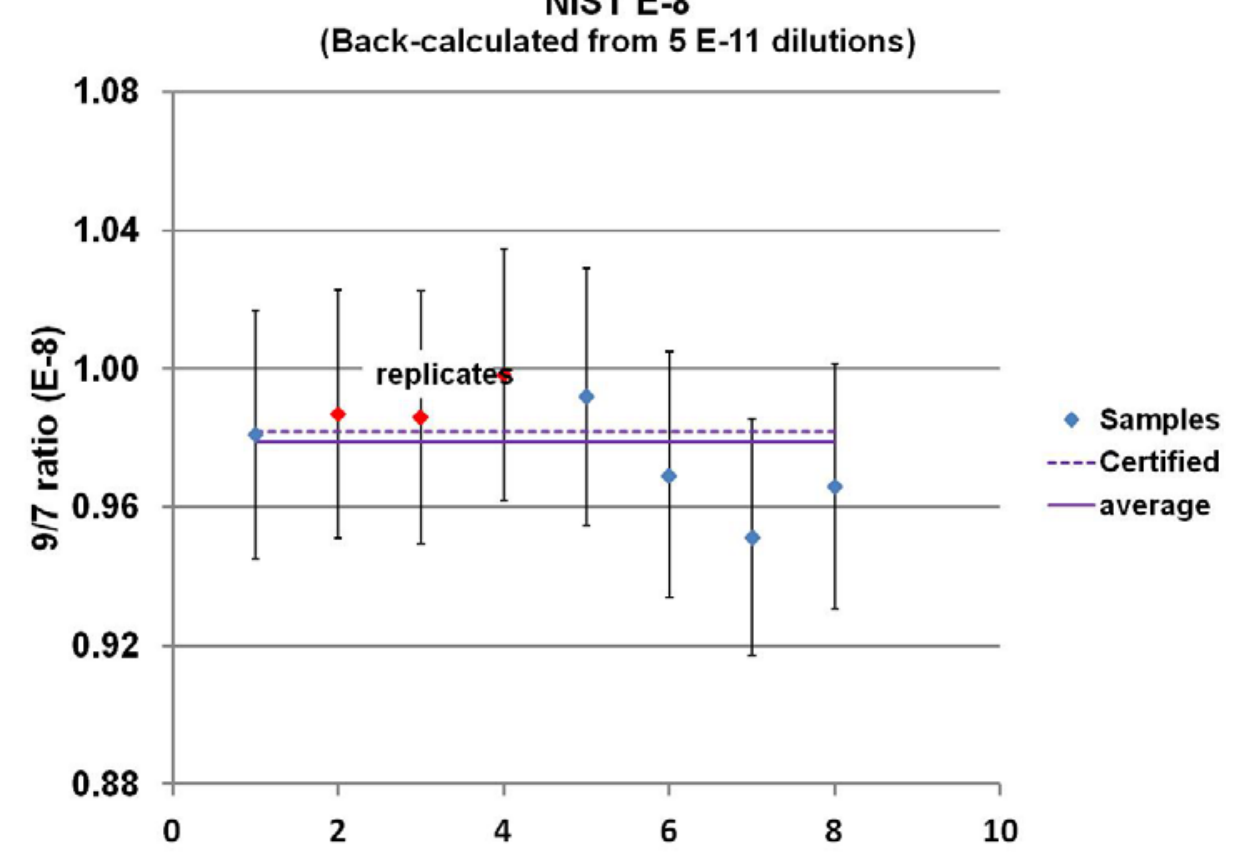

Plot 1. The plot shows the data from the NIST $1 \times 10^{-8}{ }^{129} \mathrm{I} /{ }^{127} \mathrm{I}$ (Table 4), after back-calculation to remove the effect of the added carrier. The final results are all within the 2-sigma uncertainty of each other and contain the certified value.

An additional dilution was prepared, NIST $323110^{-6}$ was diluted to $10^{-10}$. Thirty aliquots were electrodeposited for analysis in the INL AMS. Photographs 2 and 3 show the iodine (after dilution of the NIST $323110^{-6}$ standard) in cyclohexane before and after back-extraction into dilute aqueous solution of sodium bisulfite, respectively.
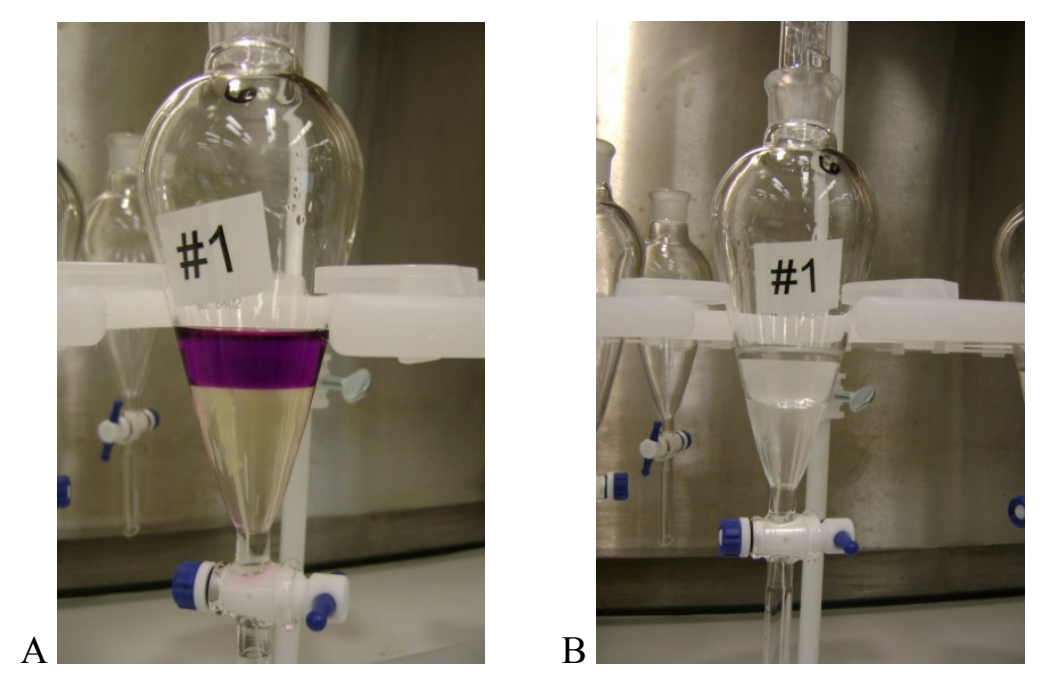

Photographs 2. and 3. Iodine in cyclohexane (A) and back extracted into dilute aqueous sodium bisulfite (B)

AMS data (after subtracting the carrier added) obtained from the $10^{-10}$ dilution is summarized in Plot 2 . The $10^{-6}$ dilution agrees at the $95 \%$ confidence level with the certificate value. 


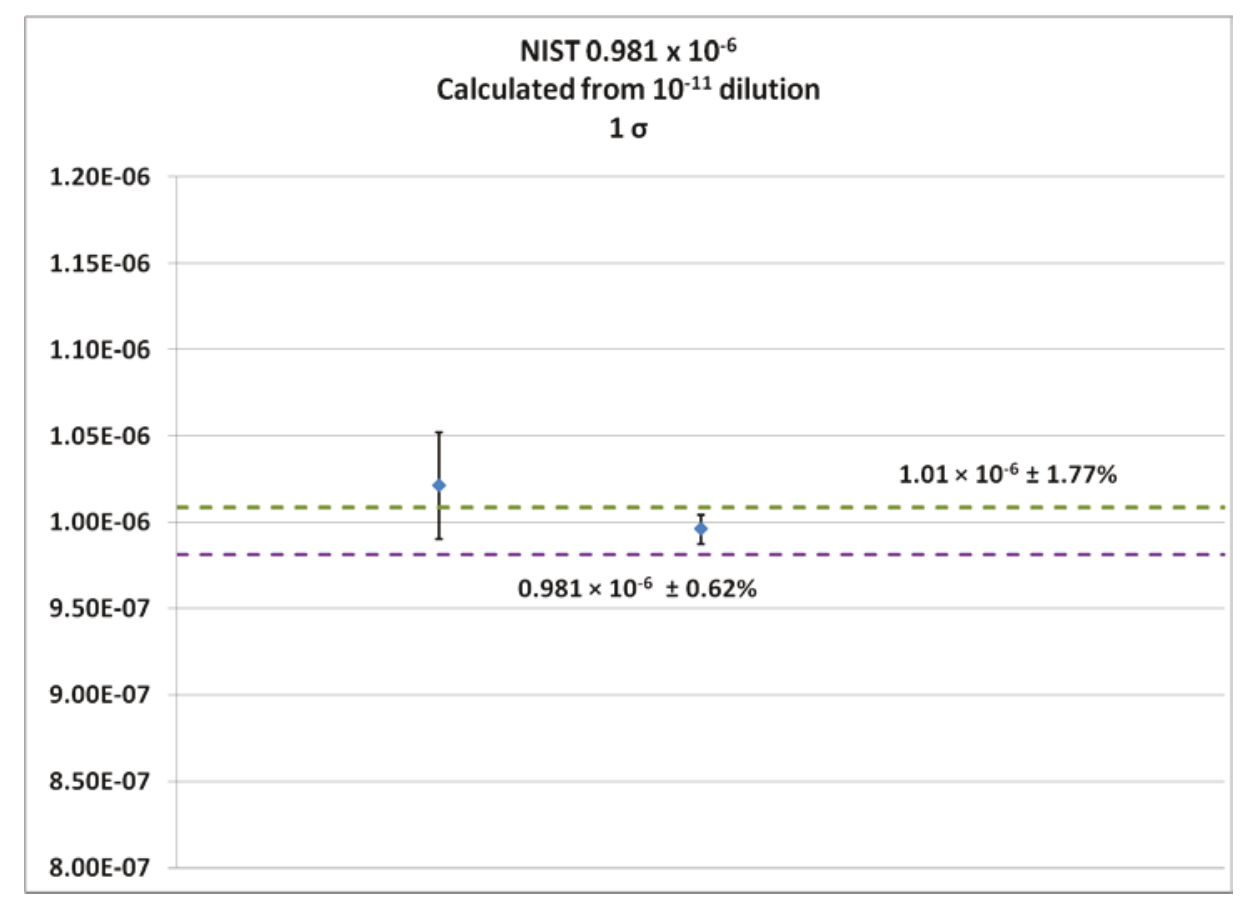

Plot 2. NIST 3231 standard diluted to E-10 (after subtracting carrier).

\subsubsection{Electrodeposition of $\mathrm{Agl}$ on Ag wire}

For ease of handling and to minimize cross-contamination of samples, the INL has developed an alternative method to prepare samples for AMS. Traditionally, iodide is precipitated as AgI and then loaded into a cathode for measurement by AMS. Handling small quantities $(\sim 3 \mathrm{mg})$ of powder is very time consuming and tedious. We have developed a method that allows us to electrochemically deposit the iodine on silver wire which can be handled with tweezers.

A diagram of the experimental setup is shown in Figure 1. The electrochemical cell is a typical three electrode setup which allows potential to be controlled at the working electrode. Fifteen centimeters of 51 $\mu \mathrm{m}$ diameter silver wire (99.95\%), mass $\sim 3 \mathrm{mg}$, [Surepure Chemetals, LLC, product \# 2702] is formed into a coiled ball by wrapping around a $1.0 \mathrm{~mm}$ rod and used as the working electrode. A Bioanalytical Systems [BAS Inc.] low leakage $\mathrm{Ag} / \mathrm{AgCl}$ reference electrode and platinum foil counter electrode are used. A cell, volume $3 \mathrm{~mL}$, was fabricated from poly-tetrafluoro-ethylene (PTFE). The solution is stirred using a PTFE coated magnetic stir bar. A photograph of the electrochemical cell during operation is shown in Photograph 3. A Bio-Logic VSP 5-channel potentiostat is used to control the electrodeposition of iodide. Photograph 4 shows a five-channel potentiostat. 


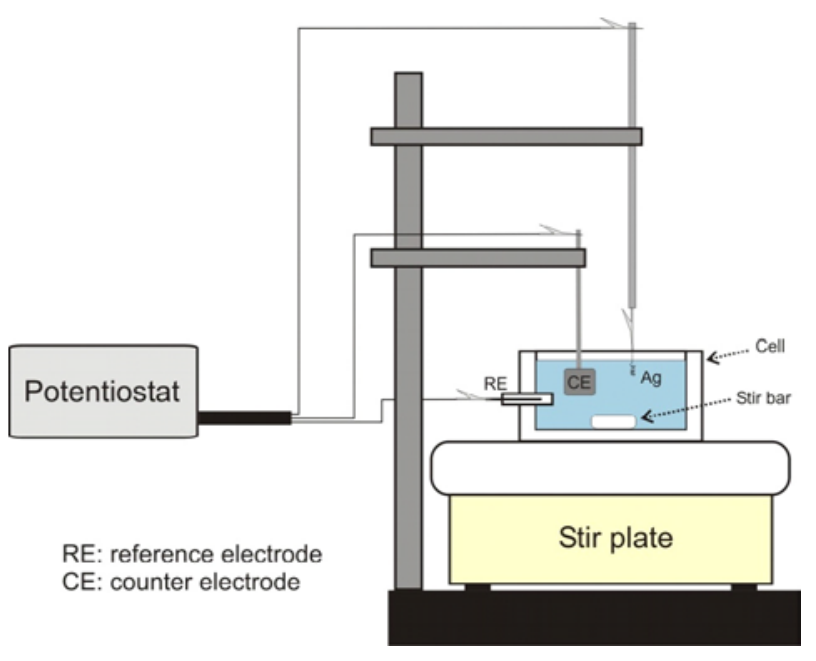

Figure 1. Diagram of electrodeposition experimental setup.

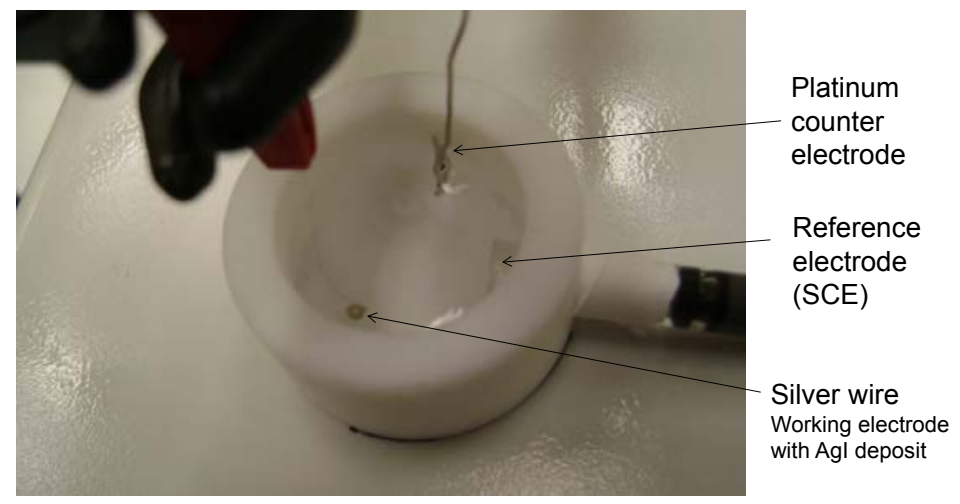

Photograph 3. Electrochemical cell during operation.

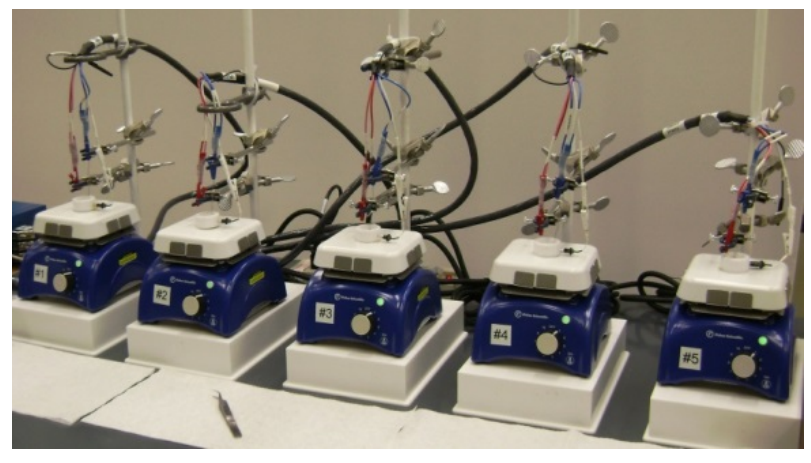

Photograph 4. Five-channel potentiostat.

A photograph of Ag wire with AgI deposit is provided in Photograph 5. The characteristic yellow color of AgI can be seen on the coil and up the "tail" to the level of the solution in the deposition cell. The "tail" used to make electrical connection also allows handling via tweezers. At the time of cathode loading the tail (without AgI deposit) is easily snapped off. 


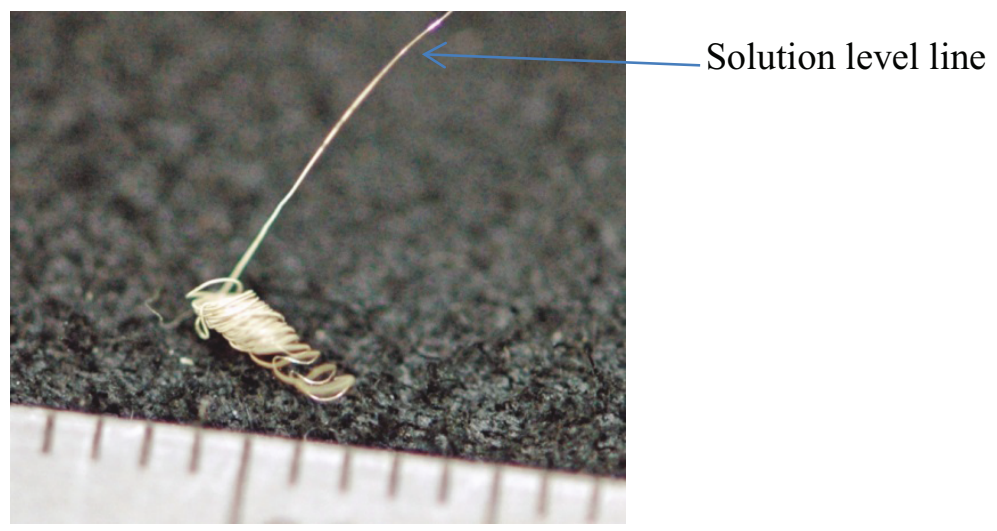

Photograph 5. Coil of $51 \mu \mathrm{m}$ silver wire with deposit of silver iodide sample material. Scale across bottom shows millimeters.

Two INL prepared $10^{-10}$ and $10^{-11}{ }^{129} \mathrm{I} /{ }^{127} \mathrm{I}$ ratio AgI standard materials were dissolved in concentrated ammonium hydroxide with zinc metal ${ }^{6}$. The resulting solution was electrodeposited on Ag wire. Ten electrodeposited samples per day on three different days were prepared and analyzed on the INL AMS. The data obtained is summarized in Plots 3 and 4. The data obtained agrees favorably with that obtained from the AgI precipitated materials. The data indicates that electrodeposition does not change the ${ }^{129} \mathrm{I} /{ }^{127} \mathrm{I}$ ratio.

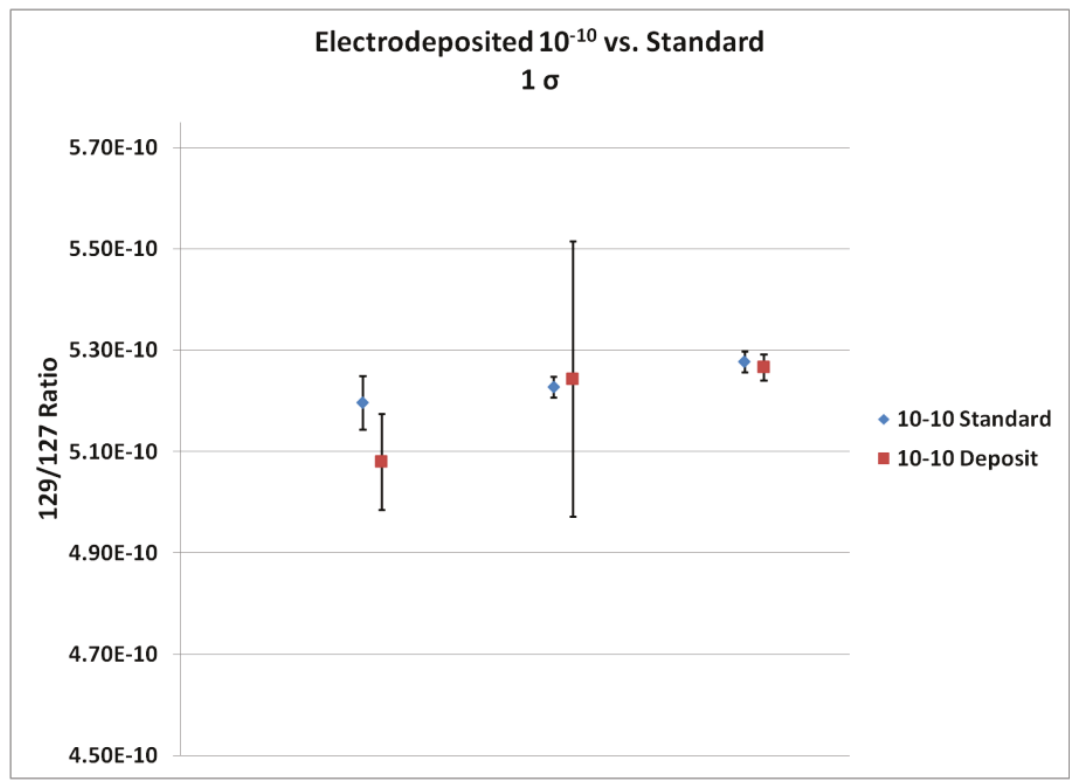

Plot 3. Comparison of electrodeposited INL E-10 standard vs. precipitated material

6 A.C. Wahl Fission of U'"' by 14-Mev Neutrons: Nuclear Charge Distribution and Yield Fine Structure Phys. Rev. 99, No. 3, (1955) 730. 


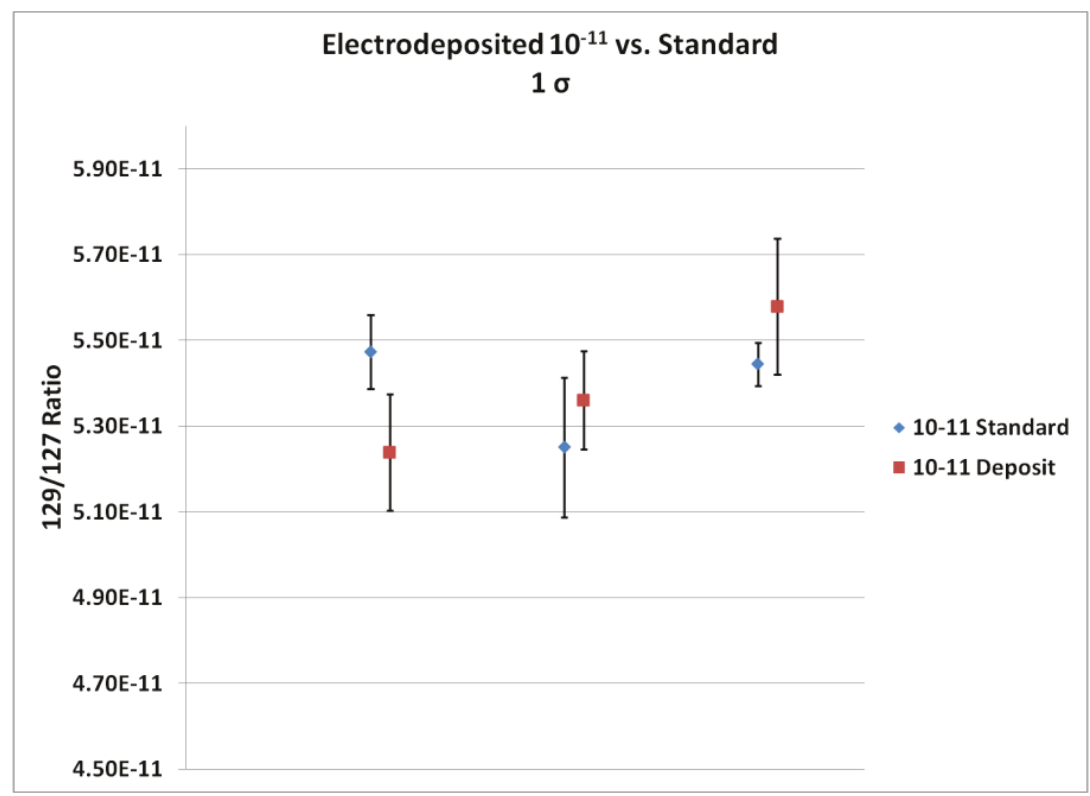

Plot 4. Comparison of electrodeposited INL E-11 standard vs. precipitated material.

\subsubsection{Preparation of Exposed Filter Samples}

Exposed filter samples consist of six layers of 3-ply polyethylene media approximately six inches wide and fifteen inches long. Photograph 6 shows a typical exposed air filter. Note the inhomogeneity of the sample on the filter media (unexposed area along the right side of the media and the darker area below it).

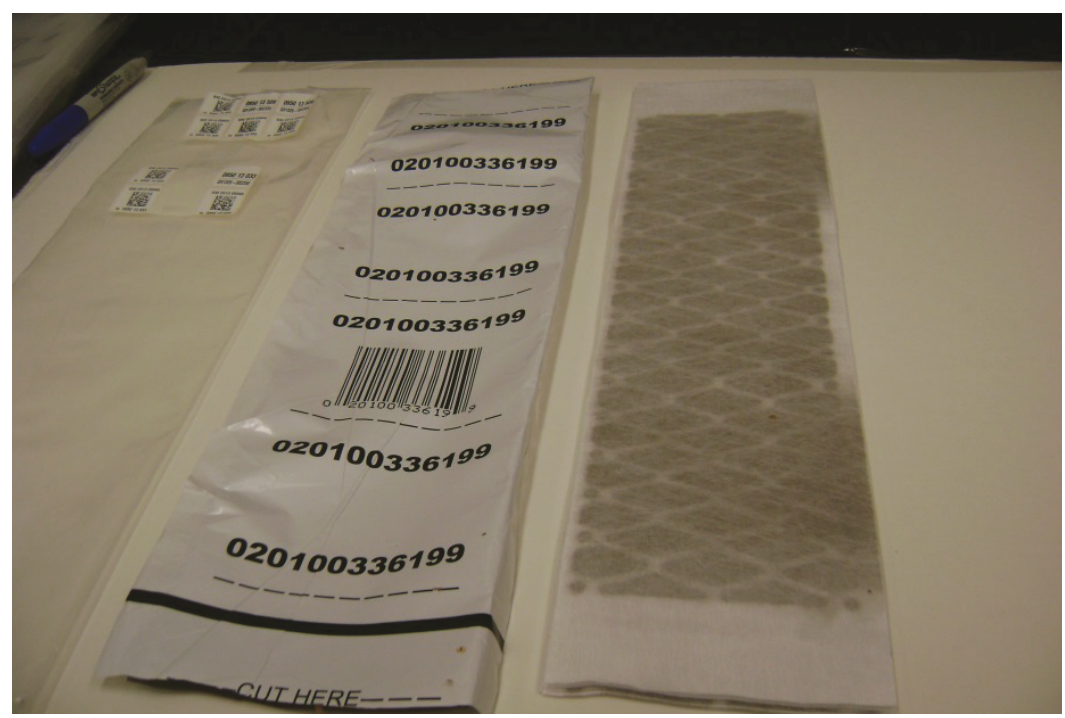

Photograph 6. Typical exposed air filter sample.

In order to be able to compare the aqueous leaching method to the benchmark or current gas phase processing and TIMS analysis, INL had to develop a method to subsample an exposed air filter. The subsampling method had to produce as close as possible equivalent and representative samples of the exposed media. 
A set of three exposed filters were cut into eight sections using a cutting guide shown in Photographs 7 and 8. An aluminum guide is placed on top of the filter and a rotary cutter is used to cut the filter media (all 6 layers) into eight pieces.
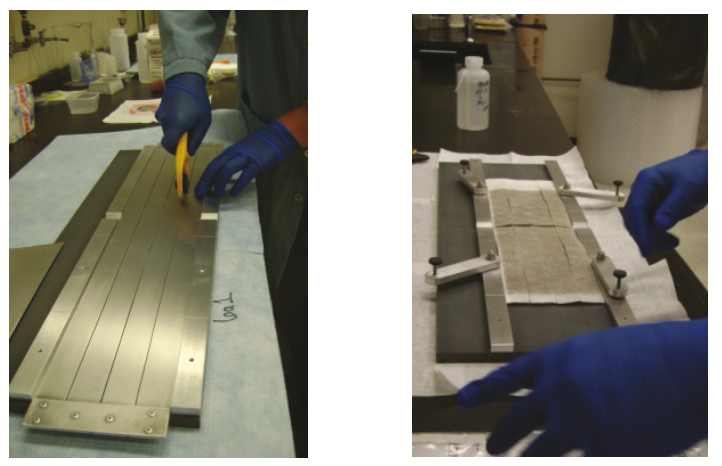

Photographs 7 and 8. Air filter sample sampling

To evaluate the distribution of iodine across the exposed filter media, each one-eighth of the filter sample was prepared by combustion/TIMS. The subsample labelling scheme is shown in Figure 2. The data obtained was used to determine the best approach to result in "equivalent or representative" filter subsamples. Atoms of ${ }^{129} \mathrm{I}$ data from three of the filters is presented below in Plots $5-7$ represent the distribution of ${ }^{129} \mathrm{I}$ atoms across an exposed air filter.
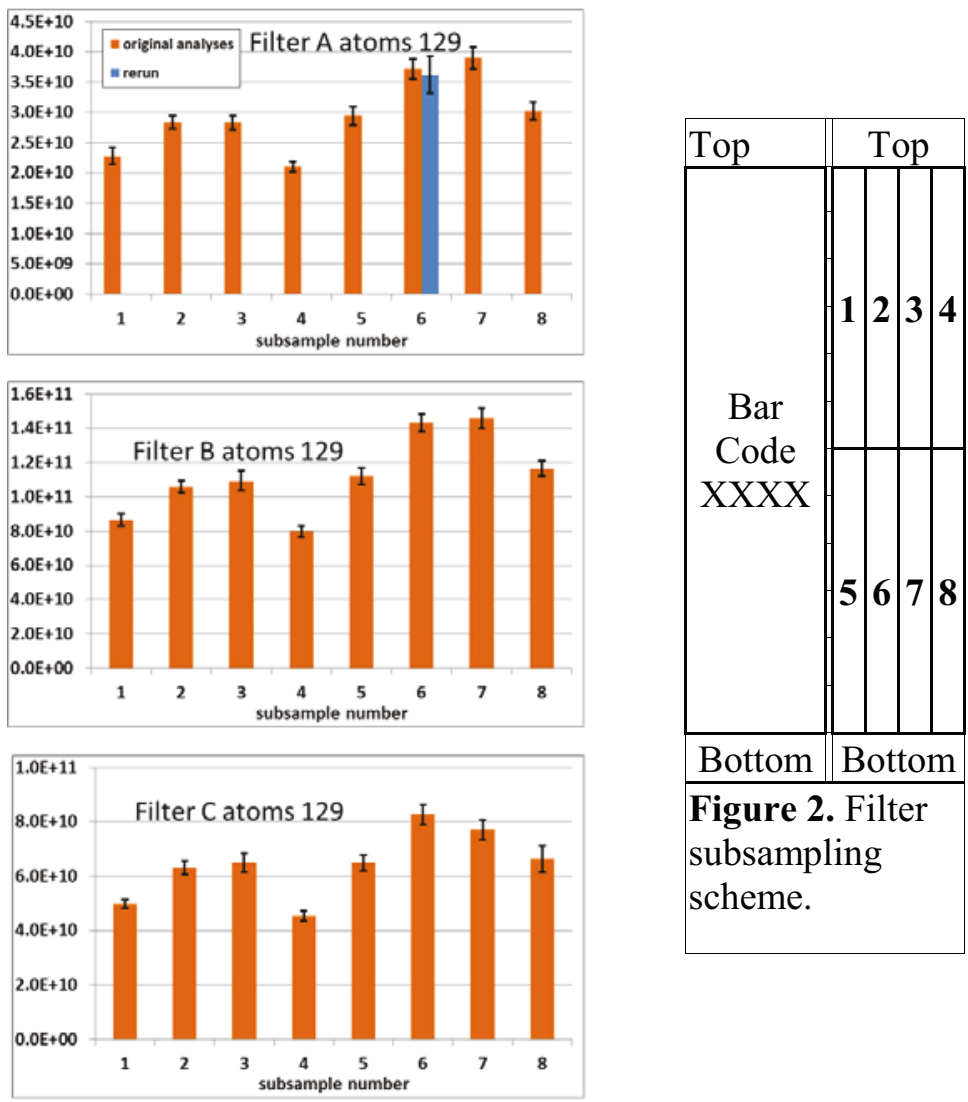

Plots 5 -7. Atoms of ${ }^{129}$ I determined by TIMS from three exposed filters cut into eight subsamples. 
The following pairs were determined to result in a representative quarter of an exposed air filter: $1 \& 7$, $2 \& 8,3 \& 5$, and $4 \& 6$. The pairing scheme is illustrated (pairs color coded) in Figure 3 . The atoms of ${ }^{129} \mathrm{I}$ from the three exposed filters were combined into quarters; the data obtained is summarized in Plots 8-10.
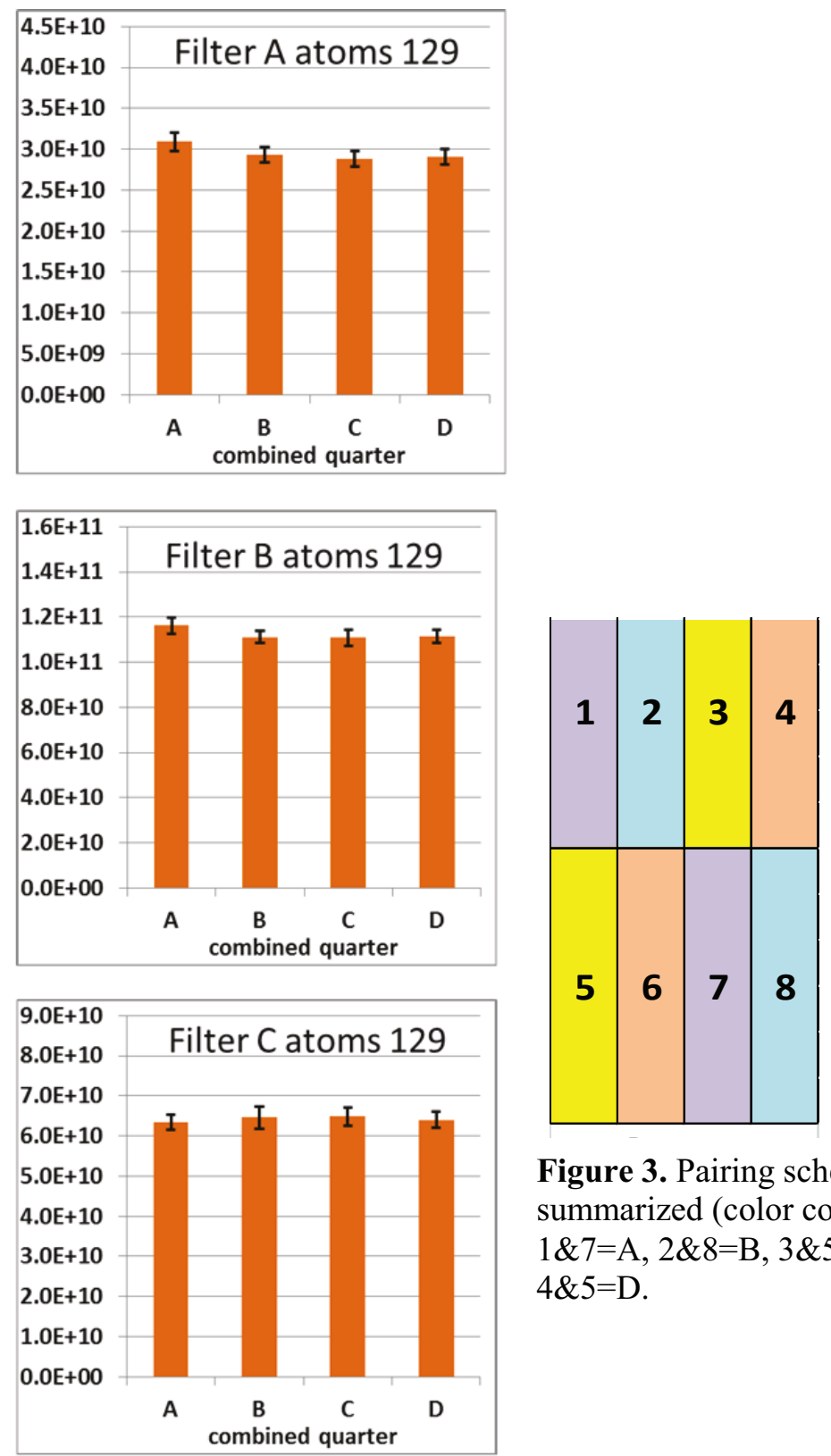

Figure 3. Pairing scheme is summarized (color coded). $1 \& 7=\mathrm{A}, 2 \& 8=\mathrm{B}, 3 \& 5=\mathrm{C}$ and $4 \& 5=\mathrm{D}$.

Plots 8-10 Atoms of ${ }^{129}$ I from three exposed filters combined into quarters. 
Seventeen exposed filter samples were cut in to eight pieces and then paired into quarters based on the scheme presented above. One quarter of each exposed filter was prepared by the current combustion /TIMS method and a different quarter was prepared using aqueous leaching/AMS method. The aqueous leaching method was modified to include the addition of IPA to remove the electrostatic charge on the filter media. ${ }^{7}$ Photographs 9 and 10 show the filter media after the addition of IPA and then IPA $/ 5 \%$ TMAH, respectively. The samples were leached overnight ( $\sim 18$ hours) in an ultrasonic bath at $90{ }^{\circ} \mathrm{C}$.
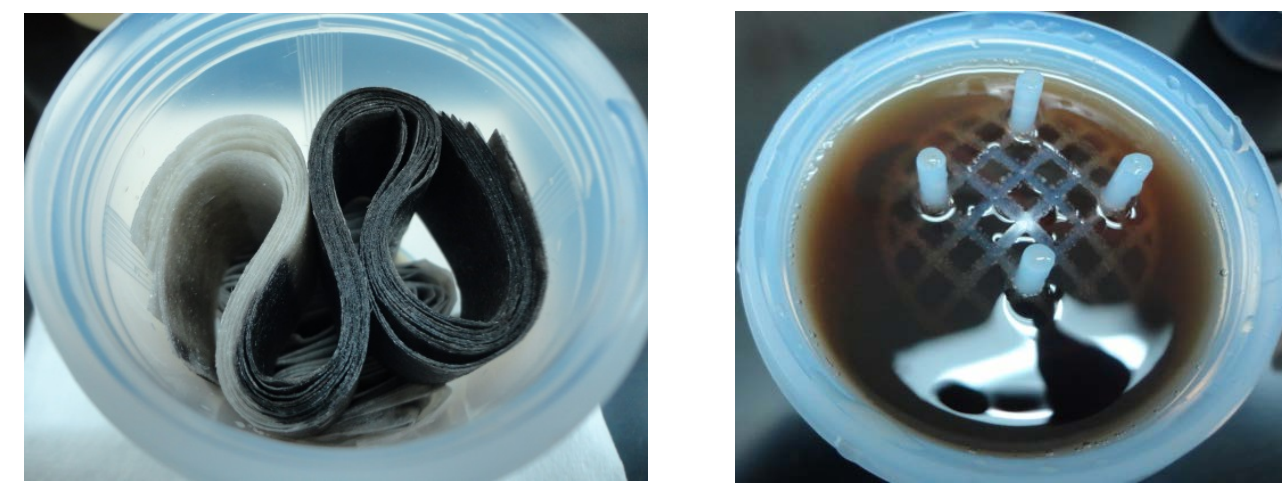

Photographs 9 and 10 Exposed filter after the addition of IPA and after addition of IPA/TMAH.

After the leachates had cooled, a 1:10 dilution was prepared from $1 \mathrm{~mL}$ of leachate and analyzed for ${ }^{127} \mathrm{I}$ by ICP-MS. Using that data, a known quantity of ${ }^{127} \mathrm{I}$ carrier was added to $1 \mathrm{~mL}$ of leachate. To ensure isotopic equilibrium, the sample/carrier was taken through oxidation reduction treatment to yield a dilute aqueous sodium bisulfite solution. Aliquots of the sodium bisulfite solution were added to the electrodeposition cell to result in approximately $25-50 \mu \mathrm{g}$ of total iodine on a $3 \mathrm{mg}$ silver wire.

AMS cathodes were prepared from the aqueous leachates described above and analyzed at INL. The atoms of ${ }^{129}$ I obtained by both methods compare favorably and is shown in Plots 11 and 12.

\footnotetext{
${ }^{7}$ A. L. Sanchez, J. A. Hubbard, J. G. Dellinger, and B. L. Servantes, Experimental Study of Electrostatic Aerosol Filtration at Moderate Filter Face Velocity, Aerosol Science and Technology, 47 (2013) 606.
} 


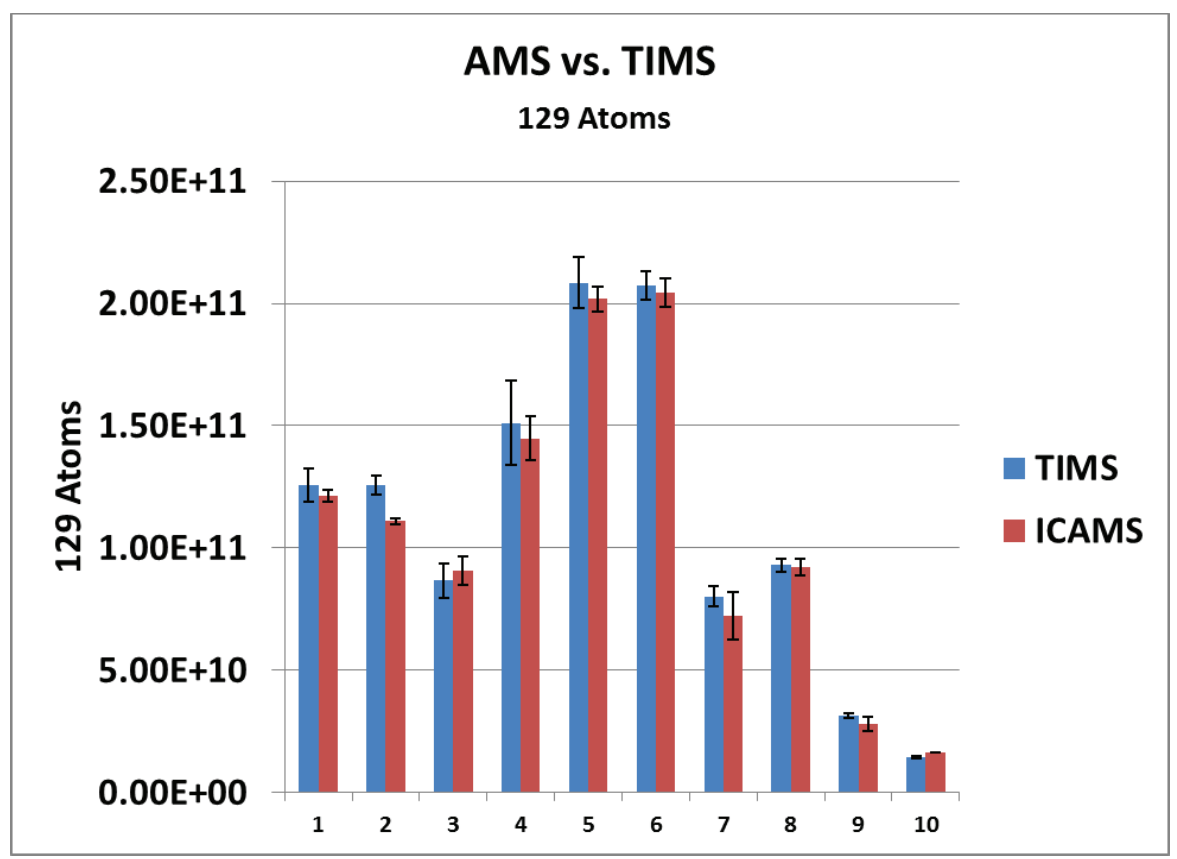

Plot 11. Comparison of TIMS and INL AMS results for exposed filters.

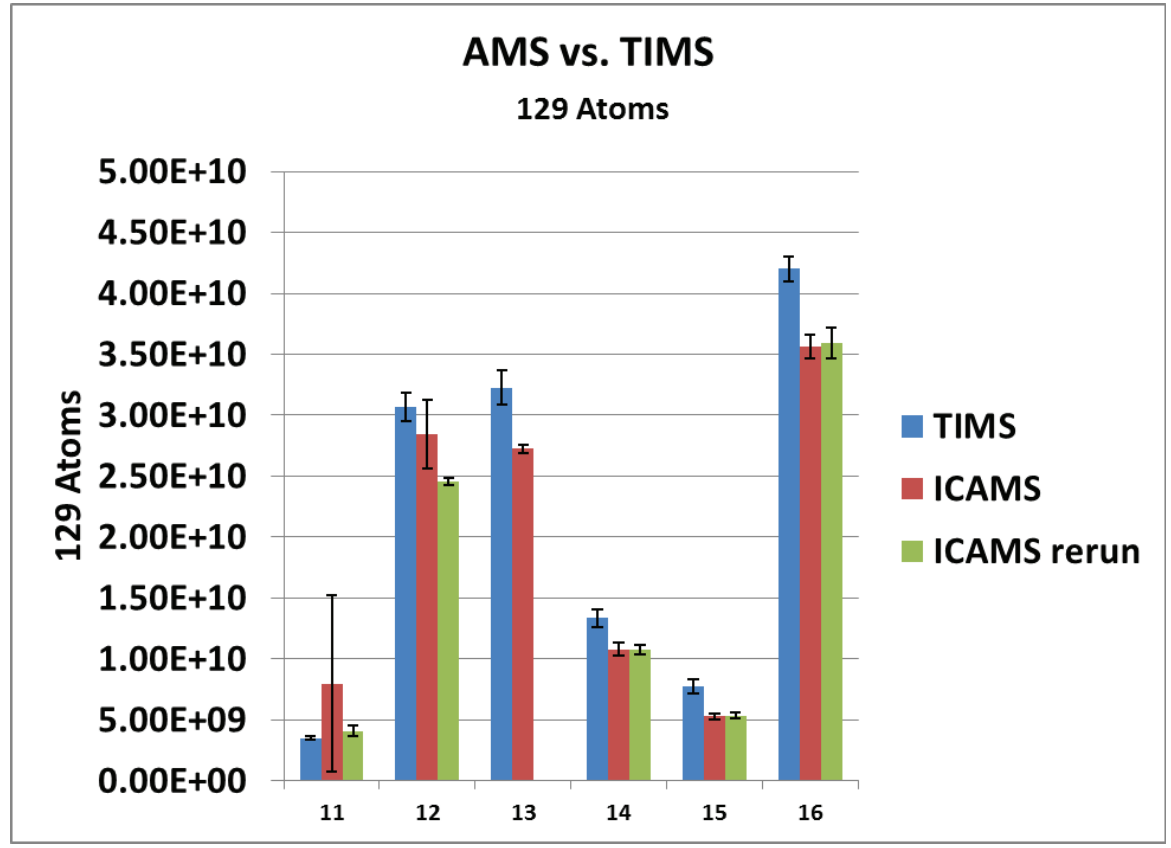

Plot 12. Comparison of TIMS and INL AMS results for exposed filters.

To verify that all the iodine had been removed via the aqueous leaching, the leached media was rinsed five times with MilliQ water, combusted and processed through the gas phase method and analyzed by TIMS. The TIMS results indicate that $81-100 \%$ of the iodine on the exposed filter was removed during the aqueous leach. The data is summarized in Table 5. The second column is the total micrograms on the filter media determined by leaching in IPA/TMAH and analysis by ICP-MS. The third column is the result from a separate quarter of the exposed filter, processed via gas phase separation and TIMS analysis. The fourth column is the determination of iodine remaining on a leached filter residue prepared by gas 
phase processing and TIMS analysis. The fifth column is the calculated percentage removed by the leach method.

\begin{tabular}{|c|c|c|c|c|}
\hline \multicolumn{5}{|c|}{ Iodine Content of Whole Filter } \\
\hline Sample ID & $\begin{array}{c}\text { Leach Method } \\
\boldsymbol{\mu} \mathbf{g} \\
(\mathrm{ICP}-\mathrm{MS}) \\
\text { A }\end{array}$ & $\begin{array}{c}\text { Combustion } \\
\text { Method } \\
\boldsymbol{\mu g} \\
\text { (TIMS) } \\
\text { B }\end{array}$ & $\begin{array}{c}\text { Leach } \\
\text { Residue } \\
\mu \mathrm{g} \\
\text { (TIMS) } \\
\text { C }\end{array}$ & $\begin{array}{l}\text { \% Removed by } \\
\text { Leach Method } \\
\text { A / }(\mathrm{A}+\mathrm{C})\end{array}$ \\
\hline 1 & 94.35 & 82.49 & 3.06 & 96.86 \\
\hline 2 & 71.40 & 65.61 & 2.30 & 96.88 \\
\hline 3 & 53.94 & 55.48 & 1.82 & 96.74 \\
\hline 4 & 60.60 & 58.86 & 2.72 & 95.70 \\
\hline 5 & 80.21 & 75.74 & 3.44 & 95.89 \\
\hline 6 & 64.98 & 60.55 & 4.11 & 94.05 \\
\hline 7 & 14.23 & 14.07 & 0.93 & 93.87 \\
\hline 8 & 8.85 & 7.87 & 0.019 & 99.79 \\
\hline 9 & 17.03 & 15.57 & 3.95 & 81.17 \\
\hline 10 & 18.70 & 18.40 & 3.79 & 83.15 \\
\hline 11 & 10.76 & 8.94 & 1.52 & 87.62 \\
\hline $121 \& 7$ & 8.67 & 7.97 & 1.14 & 88.38 \\
\hline $124 \& 6$ & 8.70 & 7.97 & 1.13 & 88.50 \\
\hline $\begin{array}{l}\text { Filter blank no } \\
\text { leach }\end{array}$ & N/A & 0.91 & N/A & \\
\hline $\begin{array}{c}\text { Filter blank } \\
\text { after leaching }\end{array}$ & N/A & N/A & 0.31 & \\
\hline $\begin{array}{l}\text { Filter blank } \\
\text { after leaching }\end{array}$ & $\mathrm{N} / \mathrm{A}$ & N/A & 0.15 & \\
\hline
\end{tabular}

Table 5. Percentage of iodine removed by aqueous leaching process. 


\subsection{Task 4.1, extension Extraction of Charcoal Filters}

Having shown success with the extraction of exposed air filters, our effort turned to extracting a new matrix (charcoal). Charcoal filters are used extensively to collect iodine. Charcoal samples were extracted with $5 \% \mathrm{TMAH}$ at $90^{\circ} \mathrm{C}$ for $\sim 8$ hours. A photograph of the sample prior to heating is provided in Photograph 11 . The preliminary results indicated that $98 \%$ of the iodine was removed. The leached charcoal samples were combusted and analyzed by TIMS to determine if any iodine remained on the charcoal. The combustion/TIMS data are summarized in Table 6.

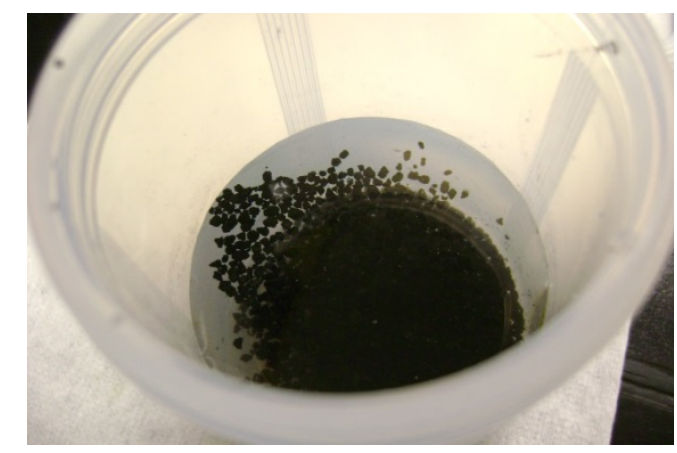

Photograph 11. Charcoal sample prior to heating.

\begin{tabular}{|c|c|c|c|c|}
\hline \multicolumn{5}{|c|}{ Iodine Content of Charcoal Filter } \\
\hline \multirow{2}{*}{ Sample ID } & $\begin{array}{c}\text { Leach Method } \\
\boldsymbol{\mu g} \\
\text { (ICP-MS) } \\
\text { A }\end{array}$ & $\begin{array}{c}\text { Combustion } \\
\text { Method } \\
\boldsymbol{\mu g} \\
(\mathrm{TIMS}) \\
\text { B }\end{array}$ & $\begin{array}{c}\text { Leach } \\
\text { Residue } \\
\boldsymbol{\mu g} \\
(\mathrm{TIMS})\end{array}$ & $\begin{array}{c}\text { \% Removed } \\
\text { by Leach } \\
\text { Method }\end{array}$ \\
\hline 1 & 15.04 & 31.8 & 9.17 & A / (A + C) \\
\hline 2 & 8.27 & 10.3 & 4.21 & 62.12 \\
\hline 3 & 13.30 & 30.7 & 5.13 & 72.16 \\
\hline
\end{tabular}

Table 6. Removal of iodine from charcoal samples. 


\subsection{Task 4.2 Detection Limit Determination}

The determination of the ${ }^{127}$ I detection limit was successful for a 0.5 -MV AMS system using the electrodeposited iodine on silver wire to prepare cathodes. The limit of $10 \mu \mathrm{g}$ of iodine is required for a positive detection on the 0.5-MV AMS at ETH - Zurich (Swiss Federal Institute of Technology). Samples were included for the detection limit determination, with multiple sets run throughout the project. The data indicate that when the amount is less than $10 \mu \mathrm{g}$, the uncertainty in the results from samples with a ${ }^{129} \mathrm{I} /{ }^{127} \mathrm{I}$ isotopic ratio of $\sim 2 \times 10^{-10}$ increases dramatically due to the small number of counts from the detection of ${ }^{129} \mathrm{I}$. This is illustrated in Plot 13, which show the large increase in the standard deviation of the sample results when the 5 and $1-\mu \mathrm{g}$ samples were analyzed. Below $1 \mu \mathrm{g}$ of iodine, the data quality deteriorates rapidly.

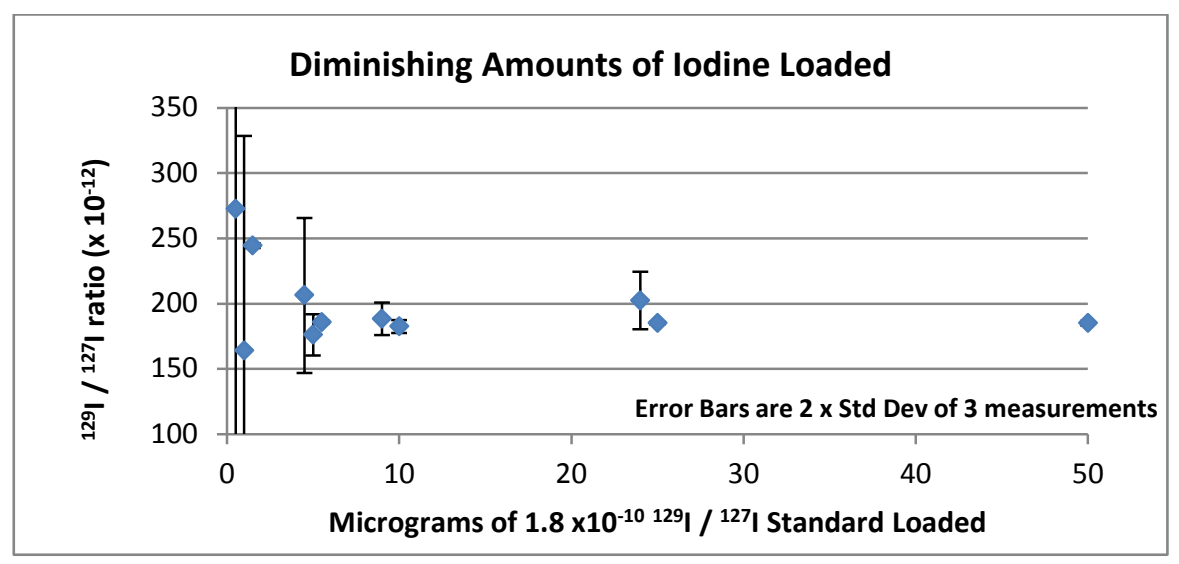

Plot 13. Iodine isotopic ratios measured by AMS at ETH using electrodeposition on silver wire as the method of preparation. 


\subsection{Task 4.3 Standard Materials for Quality Assurance}

The goal of this effort was to synthesize a suite of isotopic iodine standards in the form of silver iodide for general use with the AMS system. Standard materials have been produced at four different ${ }^{129} \mathrm{I} /{ }^{127} \mathrm{I}$ levels for quality assurance of AMS operations and data. The ${ }^{129} \mathrm{I} /{ }^{127} \mathrm{I}$ ratios of the standards were nominally prepared to be $5 \times 10^{-10}, 5 \times 10^{-11}, 5 \times 10^{-12}$, and a ${ }^{129} \mathrm{I}$ blank. The quantities produced are sufficient for long-term use.

The key to successful blending of isotopic materials is taking the mixed materials through an oxidationreduction step. The redox reaction is sufficient to achieve isotopic equilibration.

One pound of "Woodward Iodine" was obtained from Woodward Iodine Corporation of Woodward, Oklahoma. This product is refined from brines pumped from deep wells in Oklahoma. The brines are very old; therefore, they are free of contamination from anthropogenic ${ }^{129} \mathrm{I}$. Woodward iodine is widely used in the AMS community as a blank material.

The Woodward material was spiked with the appropriate aliquots of a National Institute of Standards and Technology (NIST) Standard Reference Material, SRM-3231, Iodine-129 Isotopic Standard (High-Level). The certified ${ }^{129} \mathrm{I} /{ }^{127} \mathrm{I}$ ratio is $0.981 \times 10^{-6}$ in a $0.007 \underline{\mathrm{M}}$ solution of sodium iodide in a matrix of sodium hydroxide, with sodium sulfite as a preservative.

For Task 4.3, standard materials were established for AMS quality control and instrument evaluation. Multiple analyses have been conducted on the materials. Table 7 shows the success that was achieved with this effort. The standard materials are being reported to contain the ratios that were targeted in their manufacture.

\begin{tabular}{|c|c|c|c|c|}
\hline Designation & $\begin{array}{c}\text { Amount of } \\
\text { AgI Prepared }\end{array}$ & $\begin{array}{c}\text { Desired } \\
{ }^{129} \mathbf{I} \mathbf{}^{\mathbf{2 7}} \mathbf{I}\end{array}$ & $\begin{array}{c}\text { Weighted Average } \\
\mathbf{1 2 9}_{\mathbf{I}} \mathbf{}^{\mathbf{1 2 7}} \mathbf{I}\end{array}$ & $\begin{array}{c}\text { Uncertainty in Weighted } \\
\text { Average (1 sigma) }\end{array}$ \\
\hline $\mathrm{B}$ & $16.75 \mathrm{~g}$ & - & $8.71 \times 10^{-14}$ & $0.79 \times 10^{-14}$ \\
\hline $\mathrm{C}$ & $23.38 \mathrm{~g}$ & $5 \times 10^{-11}$ & $4.95 \times 10^{-11}$ & $0.12 \times 10^{-11}$ \\
\hline $\mathrm{D}$ & $20.17 \mathrm{~g}$ & $5 \times 10^{-10}$ & $4.44 \times 10^{-10}$ & $0.20 \times 10^{-10}$ \\
\hline $\mathrm{E}$ & $19.49 \mathrm{~g}$ & $5 \times 10^{-12}$ & $4.71 \times 10^{-12}$ & $0.09 \times 10^{-12}$ \\
\hline
\end{tabular}

Table 7. Standard material make-up and measured values. The average is weighted by the number of analyses at the independent laboratories and inversely by the uncertainty reported.

The data from the other laboratories shows a discrepancy in the results. There is good precision at each laboratory, showing the standard materials prepared are homogenous. The differences come down to calibration standards. There is no common standard for the laboratories for comparison. This led to the decision that the materials prepared for use at INL would be best calibrated to NIST standards, as opposed to the round robin analysis that was done. The results of this calibration are shown in Table 8 and represent the values to be used by INL moving forward for these materials.

\begin{tabular}{|c|c|c|c|}
\hline Designation & Name & $\begin{array}{c}\text { Result (weighted } \\
\text { average) }\end{array}$ & Uncertainty (1 sigma) \\
\hline $\mathrm{C}$ & $5 \times 10^{-10}{ }^{129} \mathrm{I} /{ }^{127} \mathrm{I}$ & $5.49 \times 10^{-10}$ & $2.35 \times 10^{-12}(0.43 \%)$ \\
\hline $\mathrm{D}$ & $5 \times 10^{-11}{ }^{129} \mathrm{I}^{127} \mathrm{I}$ & $5.49 \times 10^{-11}$ & $2.48 \times 10^{-13}(0.45 \%)$ \\
\hline $\mathrm{E}$ & $5 \times 10^{-12}{ }^{129} \mathrm{I}^{127} \mathrm{I}$ & $4.43 \times 10^{-12}$ & $6.52 \times 10^{-14}(1.47 \%)$ \\
\hline
\end{tabular}

Table 8. Standard material measured values calibrated to NIST 3230 standards. 


\subsection{Task 4.4 Knowledge Exchange}

\subsubsection{Conference Presentations}

In 2013, D. D. Jenson participated in the $11^{\text {th }}$ annual European Conference on the Application of Accelerators in Research and Technology (ECAART-11) held in Namur, Belgium. The primary emphasis of the conference was ion-beam techniques (such as PIXE, PIGE, RBS, and ion implantation). The conference included one oral presentation and several posters related to various aspects of AMS. INL presented a poster titled, "Alternative Method for Iodine AMS Target Preparation." Dr. Jenson obtained information about what people are doing with accelerators around the world, from irradiating gemstones to treating cancer to analyzing archaeological artifacts. Thirty-one countries were represented at the conference, with Dr. Jenson being the only scientist from the United States of America.

In 2014, M. L. Adamic, J. E. Olson, and M. G. Watrous attended the $13^{\text {th }}$ International Conference on Accelerator Mass Spectrometry, held in Aix-en-Provence, France. One poster was presented, "Iodine Standard Materials: Preparation and Inter-Laboratory Comparisons," and one oral presentation, "Electrodeposition as an alternate method for preparation of environmental samples for iodide analysis by AMS"

The oral presentation "Electrodeposition as an alternate method for preparation of environmental samples for iodide analysis by AMS" was accepted and will be published in in Nuclear Instruments and Methods in Physics Research, Section B (in press).

\subsubsection{Operating Eidgenössische Technische Hochschule (ETH) AMS}

During 2013, D. D. Jenson visited the AMS facility at ETH in Zurich, Switzerland, where the only 0.5MV AMS currently running iodine in the world resides. INL samples were loaded by Dr. Jenson of INL, who then set up the compact AMS instrument for running, optimized the system (tuning), and collected data. Photograph 12 shows him running the ETH AMS. He had an extensive list of questions that were answered and more information was gathered. Many aspects of AMS operation were discussed (e.g., cleanliness, maintenance, and materials). The time at ETH was very useful in planning further experiments and preparing for receipt and operation of the AMS instrument at INL.

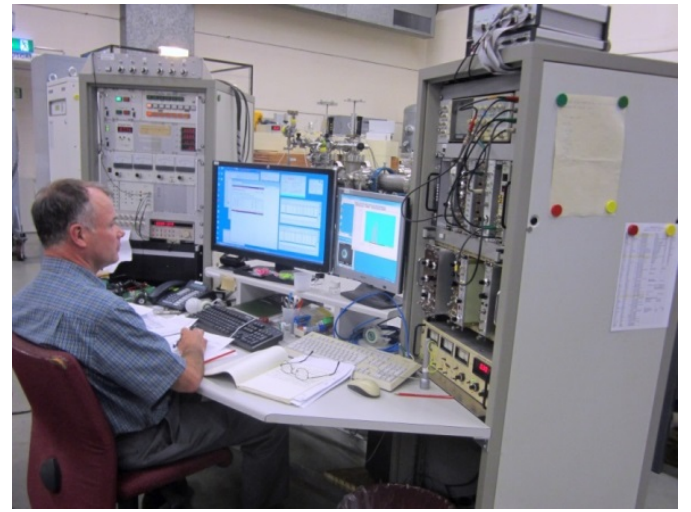

Photograph 82. INL scientist running INL-prepared samples on the AMS at ETH in Zurich in September 2013.

During 2014, J. E. Olson and D. D. Jenson spent a full week working with scientists at ETH in Zurich. The ETH AMS system is the closest approximation to the INL system presently in service. Many aspects of sample handling, system operation, data reduction, etc. were discussed. INL scientists were involved 
in sample loading, system tuning, changing from +2 to +3 charge states for operation, and also switching to analysis of actinides. Also while there, the role of copper as a cathode material was considered in the +2 charge state. We had submitted some samples previously in copper cathodes; the analytical results had been unsatisfactory. It was quickly evident that there was interference at mass 129 . The culprit was identified as ${ }^{63} \mathrm{Cu}^{65} \mathrm{CuH}^{-}$(mass 129) which had lost about $1 \%$ of its initial energy going through the system.

\subsubsection{Visits to other AMS Laboratories}

\subsubsection{University of California - Irvine}

In addition to working with ETH in Zurich to gain experience with running iodine by AMS, INL leveraged some of the expertise in the United States. Specifically, the WM Keck Carbon Cycle Accelerator Mass Spectrometry Laboratory, located at the University of California - Irvine, offered a great opportunity for INL scientists. The facility is headed up by John Southon, a former Livermore accelerator expert. Mark Roberts, a staff physicist from Woods Hole Oceanographic Institution's National Ocean Sciences AMS Facility, and John Southon designed a new stripper cell for the compact AMS instruments they are operating. Although this instrument is used for radiocarbon measurements, it is very similar to the INL AMS. John and Mark were scheduled to install the new stripper cell in the University of California -Irvine instrument in September 2013 and invited J. E. Olson to be present during the instrument modifications. Because INL has a long history of modifying instruments to improve their performance, INL seized this chance to get hands-on experience of upgrading a major portion of an accelerator.

\subsubsection{Lawrence Livermore National Laboratory}

In December 2013, M. G. Watrous visited Lawrence Livermore National Laboratory in conjunction with the LLNL analyses of the INL standard materials. Although the AMS system there is much larger than the INL system (10 million volts vs. $0.5 \mathrm{MV})$, there are many similarities and discussions were fruitful. 


\subsection{Task 4.5 AMS sample analysis and cross comparison studies (INL and ETH)}

Ten exposed filter samples were prepared using the aqueous leaching method, carrier addition, and electrodeposition. The samples were pressed into titanium cathodes and sent to ETH for analysis. The data obtained is compared to data from the INL AMS in plots 14 and 15 below.

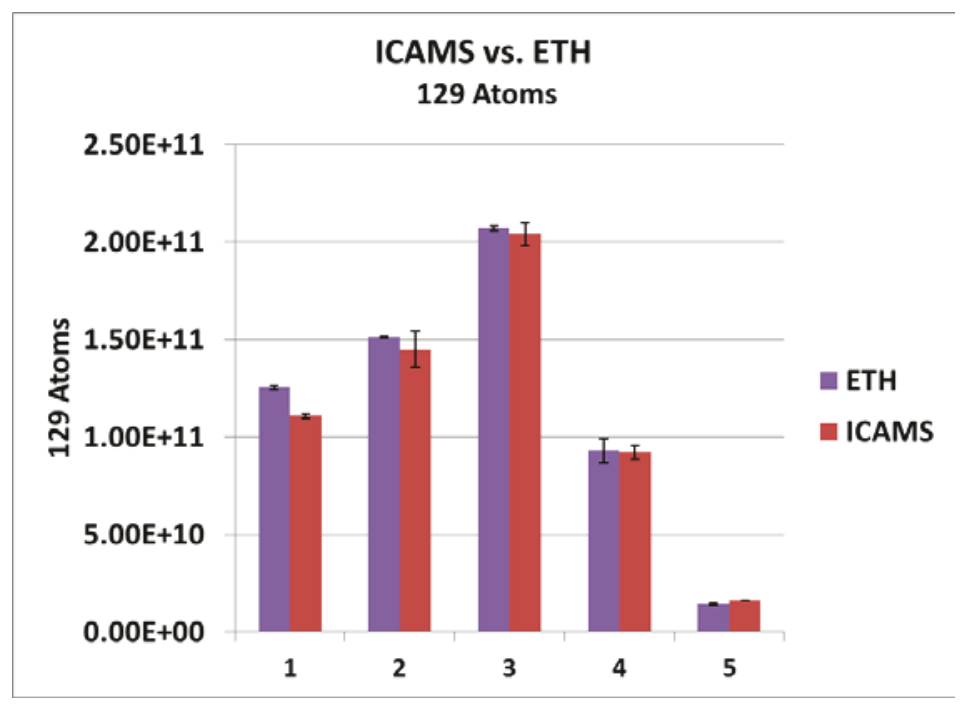

Plot 14. Comparison of INL and ETH AMS results for exposed filters.

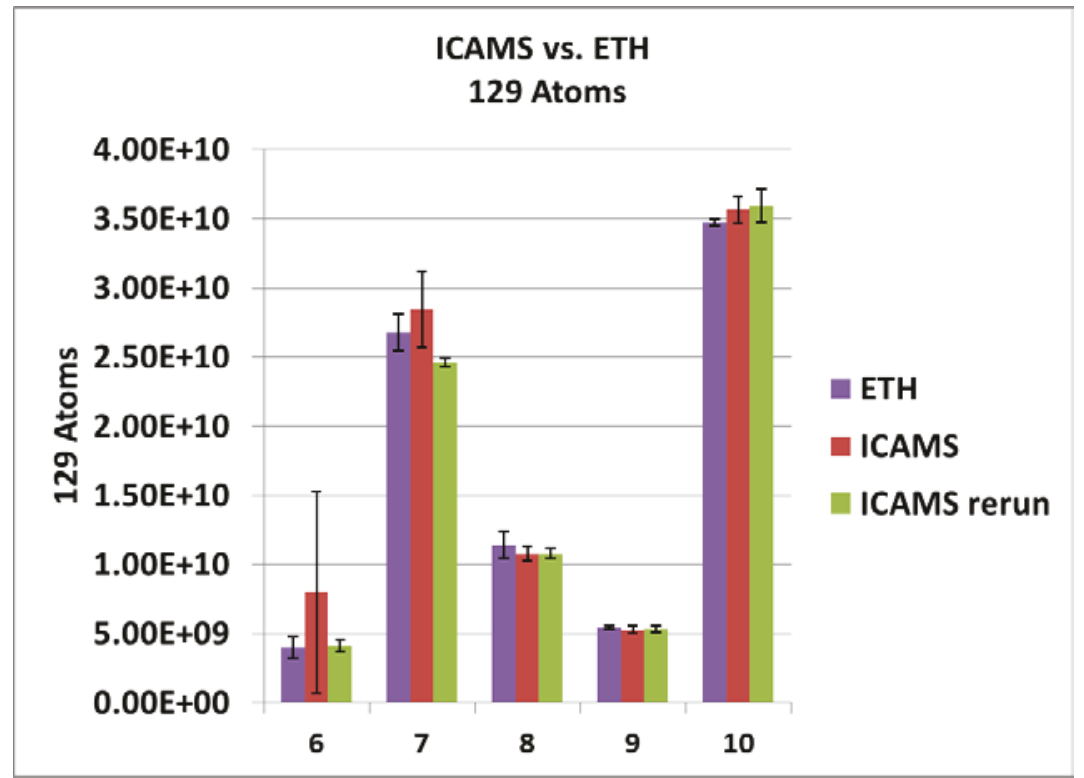

Plot 15. Comparison of INL and ETH AMS results for exposed filters. 


\subsection{Task 4.6 Supercritical Fluid Extraction of lodine}

The goal of this subtask is to develop a supercritical $\mathrm{CO}_{2}\left(\mathrm{sc}-\mathrm{CO}_{2}\right)$ extraction technique to solubilize and extract iodine species from filter paper media, and then capture iodine in a trap solution for further quantitative analysis. Research in the area of metal extraction using sc- $\mathrm{CO}_{2}$ is quite extensive; however, using sc- $\mathrm{CO}_{2}$ to extract iodine is not well known. If the principles of metal extraction in $\mathrm{sc}-\mathrm{CO}_{2}$ are applied to the extraction of iodine, it can be thought that ionic species of iodine (e.g., $\mathrm{IO}_{3}{ }^{-}$) are not soluble in sc- $\mathrm{CO}_{2}$ and must be chemically altered to charge neutral species in order to extract. Iodine species such as $\mathrm{I}_{2}$ would more likely be soluble (or mobile) in $\mathrm{CO}_{2}$. Organo-iodine species, or complexed iodine species would also likely be soluble in a non-polar solvent such as $\mathrm{CO}_{2}$. With those ideas in mind, reducing agents and strong mineral acid adducts were tested in simple benchtop liquid experiments to dissolve and reduce iodate to iodine. Visual observation of color change was used to indicate change in oxidation states. Iodate, $\mathrm{IO}_{3}{ }^{-}$is the predominant species in the atmosphere and has a high oxidation state of +5 ; thus, $\mathrm{IO}_{3}{ }^{-}$would be the most difficult of the iodine species to solubilize in sc- $\mathrm{CO}_{2}$. The hypothesis is to start with the highest oxidation state of iodine and attempt to reduce $\mathrm{IO}_{3}{ }^{-}$to $\mathrm{I}_{2}$ in sc- $\mathrm{CO}_{2}$ and capture $\mathrm{I}_{2}$ in a trap solution; thus, any ionic iodine species present will be converted to the soluble $\mathrm{I}_{2}$ form.

It is known $\mathrm{I}_{2}$ is capable of and will adsorb to surfaces such as glassware and form complexes with iron in type 316 stainless steel. Therefore, all glassware used was acid washed and the entire sc- $\mathrm{CO}_{2}$ system was passivated with $20 \% \mathrm{HNO}_{3}$ at $65^{\circ} \mathrm{C}$ for at least 30 minutes before each experiment. This process was thought to oxidize the $\mathrm{Fe}-\mathrm{O}$ sites to prevent $\mathrm{I}_{2}$ from complexation. Filter paper was cut into $1 \mathrm{x} 1$ inch squares and a known amount of aqueous iodine in the form of $\mathrm{IO}_{3}{ }^{-}$was pipetted onto the filter paper. Aqueous-based spike samples were allowed to dry overnight onto the paper.

Extraction Using Adducts: The strong mineral acid adduct, TBP $\left(\mathrm{HNO}_{3}\right)_{3.95}\left(\mathrm{H}_{2} \mathrm{O}\right)_{1.30}$, was prepared fresh daily by contacting a v/v ratio of 0.75 fuming nitric acid with 1.00 tri-n-butyl phosphate. This adduct was placed into an ISCO 260D pump and metered into the sc- $\mathrm{CO}_{2}$ at a flow rate of $0.5 \mathrm{~mL} / \mathrm{min}$. The sc- $\mathrm{CO}_{2}$ extraction was conducted at a temperature and pressure of $85^{\circ} \mathrm{C}$ and $5000 \mathrm{psi}$, respectively. The flow rate was maintained at an average of $3.00 \mathrm{~mL} / \mathrm{min}$ over a period of 60 minutes and then 30 minutes of fresh $\mathrm{CO}_{2}$ was allowed to flush the system of any remaining adduct and $\mathrm{I}_{2}$. The $\mathrm{I}_{2}$ was trapped in $30 \mathrm{~mL}$ of cyclohexane in the presence or absence of $\mathrm{NaOH}$ pellets. The $\mathrm{I}_{2}$ was back-extracted by contacting the organic trap solution with an equal volume of $\mathrm{H}_{2} \mathrm{O}$ and $0.1 \mathrm{~mL}$ of $1 \mathrm{M} \mathrm{NaHSO}_{3}$ and then neutralized by combining an equal volume of tetramethyl ammonium hydroxide (TMAH) and the acidic aqueous extract. Additional $\mathrm{NaOH}$ solution was added to reach a neutral $\mathrm{pH}$. All solutions were analyzed by ICP-MS. All sc- $\mathrm{CO}_{2}$ extractions were performed in triplicates.

Extraction Using Reducing Agents: Hydroxyl amines and different extraction conditions were evaluated and will be discussed further in results and discussion section.

Extraction Using Reducing Agents: Hexane is known to be a good solvent to simulate a sc- $\mathrm{CO}_{2}$ environment without having to be in a pressurized system. Amines, amine hydrochlorides, and hydroxyl amines were the first candidates to attempt reduction of $\mathrm{IO}_{3}{ }^{-}$. The solubility of the amines was tested by combining hexane and methanol with the amine. Visual observation of single phase was confirmed for several of the amines. Those of which formed a single phase were then added to mg amounts of $\mathrm{KIO}_{3}$. Only the hydroxyl amines were observed to produce a color change. Drops of $\mathrm{HCl}$ were added to catalyze the reactions. This addition resulted in nearly all the single phase amine solutions to change from colorless to yellow or brown color. This color change was promising; thus, select amines and hydroxyl amines proceeded to be tested in $\mathrm{sc}-\mathrm{CO}_{2}$. After phase equilibria experiments, only $\mathrm{N}, \mathrm{N}-$ diethylhydroxylamine was soluble at the temperatures and pressures examined. Sc- $\mathrm{CO}_{2}$ extractions of filter papers spiked with iodine with the hydroxyl amine gave recovery below the detection limit; thus, the pursuit of amines for iodine sc- $\mathrm{CO}_{2}$ extraction was abandoned. 
Extraction Using the TBP- $\mathrm{HNO}_{3}$ adduct: Again, preliminary experiments were performed in liquid hexane before proceeding to sc- $\mathrm{CO}_{2}$. Two adducts were prepared and added to $\mathrm{KIO}_{3}$ powder. The first was made by contacting a v/v ratio of $0.25 \mathrm{HNO}_{3}$ with $1 \mathrm{TBP}$ and secondly 0.75 fuming $\mathrm{HNO}_{3}$ with 1 TBP. These were allowed to have contact with $\mathrm{KIO}_{3}$ at room temperature and at $85^{\circ} \mathrm{C}$ for 10 minutes before they were evaluated. The $0.25: 1 \mathrm{HNO}_{3}$-TBP solution did not show any visible change; however, the $0.75: 1 \mathrm{FHNO}_{3}$-TBP solution was slightly pink at $85^{\circ} \mathrm{C}$. This color change was indicative of reduction of $\mathrm{IO}_{3}{ }^{-}$to $\mathrm{I}_{2}$. The adduct is a strong oxidizing agent, so it was surprising to see this reduction proceed in a non-polar solvent. The proposed reaction is given below in Equation 1.

$$
\text { Equation } 12 \mathrm{IO}_{3}^{-}+\mathrm{NO}_{2}+10 \mathrm{H}^{+} \rightarrow \mathrm{I}_{2}+\mathrm{NO}_{3}^{-}+5 \mathrm{H}_{2} \mathrm{O}+13 \mathrm{e}^{-}
$$

Results show $64-92 \%$ of the iodate was converted to iodine by the $\mathrm{FHNO}_{3}$-TBP adduct and moved off the filter paper.

A working iodine extraction process using supercritical fluid $\mathrm{CO}_{2}$ is close at hand. A few more process and equipment adjustment will make this technique quantitative, reproducible and reliable. Future work should include the sc- $\mathrm{CO}_{2}$ system being converted to an all PEEK system with all Zero Dead Volume components. Iodine in the reactor dead space was not recovered until a liquid acid wash was applied. Further, it is uncertain whether the passivation technique is effective; therefore, the next attempts must utilize fully inert surfaces from the extraction cell onwards. Different methods to better trap the iodine after sc- $\mathrm{CO}_{2}$ would need to be tested because all of the total iodine content was not accounted for and was possibly lost via bubbling through the trap solution.

There were several technical hurdles overcome in the short time spent on this project. Different approaches were taken to attempt to reduce iodate to iodine in the $\mathrm{sc}-\mathrm{CO}_{2}$ extraction process. A successful chemical formulation was obtained. The hydroxyl amine approach was found incapable of reducing iodate; thus, was abandoned early in the project. The TBP- $\mathrm{HNO}_{3}$ adduct was successful in reducing $92 \%$ iodate to iodine in $\mathrm{sc}-\mathrm{CO}_{2}$ at $85^{\circ} \mathrm{C}$ and $5000 \mathrm{psi}$; however, results were not reproducible due to other downstream issues related to materials of construction, extractor configuration, and extract recovery issues. Over $90 \%$ of iodine may be accounted for in the entire process. It is plausible to reduce iodate to iodine in $\mathrm{sc}-\mathrm{CO}_{2}$ with the fuming $\mathrm{HNO}_{3}$-TBP adduct and move over $90 \%$ at temperature and pressure of $85^{\circ} \mathrm{C}$ and $5000 \mathrm{psi}$, respectively. However, more time and effort are required to report consistent and reproducible data. 


\subsection{Task 4.7 Extraction of iodine from seawater}

Electrochemistry offers new tools to process samples for iodine isotope analysis. This work attempts to expand the possible role of electrochemistry in processing seawater for concentration of iodine. This work continues the use of silver and silver iodine chemistry. This work includes examination of other halides $(\mathrm{AgCl}$ and $\mathrm{AgBr})$ for possible deposit interferences, electrochemical reduction of iodate to iodide, and electrochemical concentration of iodine.

In seawater, iodine is known to exist as primarily the iodate ion $\left(\mathrm{IO}_{3}{ }^{-}\right){ }^{8}$ In order to electrochemically form AgI, iodate must first be reduced to the iodide ion $\left(\mathrm{I}^{-}\right)$. Once converted to iodide, the formation of AgI should be possible using chemistry similar to that used to form deposits on Ag wire. After forming $\mathrm{AgI}$ from a large quantity of seawater the deposit can be stripped into a much smaller volume of solution, a concentrate. The complications of performing work with significant quantities of other halides $(\mathrm{Cl}$ and $\mathrm{Br}$ ) or other contaminates in seawater was unknown. The sections below outline work performed to develop electrochemical methods of concentrating iodine as AgI and stripping into blank solutions amenable to deposition on silver wire for AMS cathode preparation. As will be shown below, the work to date demonstrates the ability to electrochemically concentrate iodine as AgI with very high conversion although more work is needed to improve stripping of iodide from the AgI deposit.

Cyclic voltammetry (CV) experiments were performed to assess the electrochemistry of the halides which are all present in seawater as well as specifically examine the electrochemical window of seawater. This included examining the electrochemistry of iodide in seawater as well to see if the chemistry previously used in dilute caustic solutions translated to seawater. The experiments were performed in small solutions volumes $(\sim 20 \mathrm{~mL})$ using commercial polished disk electrodes of various metals and glassy carbon. Based on this work, there is about $0.5 \mathrm{~V}$ separation of I from $\mathrm{Cl}$ and about $0.25 \mathrm{~V}$ separation of I from $\mathrm{Br}$. An overlay of the data obtained is provided in Figure 4. Concentration will shift the potential, but this should provide room to selectively form AgI on the surface. Thus it is anticipated that stable AgI deposits can be formed while minimal to no $\mathrm{AgBr}$ and $\mathrm{AgCl}$ will be formed. This should prevent high surface area silver electrodes from becoming saturated with other halides.

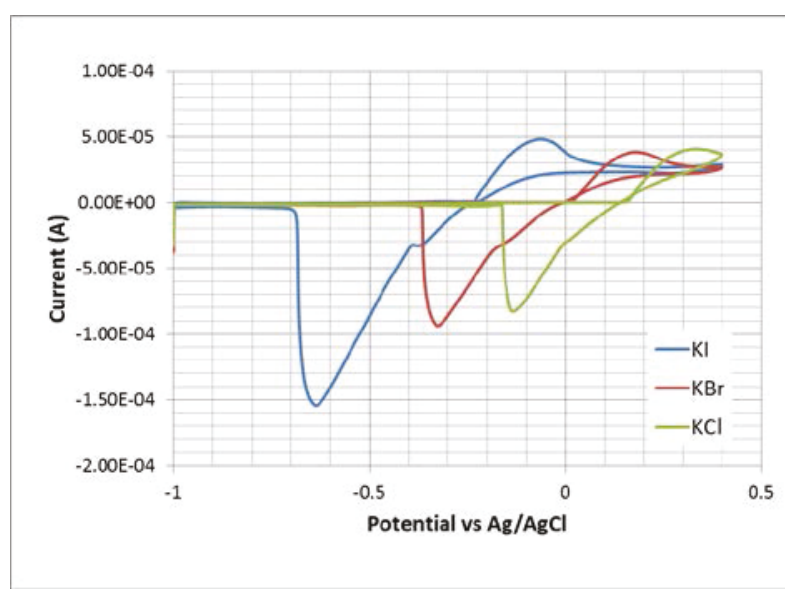

Figure 4. Cyclic voltammograms of a $\mathrm{Ag}$ disk electrode in $10 \mathrm{mM}$ solutions of $\mathrm{KI}, \mathrm{KBr}$ and $\mathrm{KCl}$.

Seawater could potentially contain redox active components or organic contaminates that affect the electrode. Thus a quick evaluation was performed to evaluate presence of any redox activity in seawater.

\footnotetext{
${ }^{8}$ V. Hansen, P. Yi, X. Hou, A. Aldahan, P. Roos and G. Possnert, Iodide and iodate $\left({ }^{129}\right.$ I and ${ }^{127}$ I) in surface water of the Baltic Sea, Kattegat and Skagerrak, Science of the Total Environment 412 (2011) 296.
} 
CV experiments in Real Ocean Water (ROW, obtained from Petco) were performed using Au and GC disk electrodes. There were no features from about $-0.2 \mathrm{~V}$ to the positive limit (where $\mathrm{Cl}$ oxidation to $\mathrm{Cl}_{2}$ occurs). Overall there does not appear to be any significant redox behavior in the region of interest (-1 V to $0.5 \mathrm{~V}$ ) that should interfere with the iodine chemistry.

The electrochemical response of $\mathrm{I}^{-}$was observed in seawater to assess the deposition and stripping curve shape. CV experiments were performed in $1 \mathrm{mM} \mathrm{KI}$ added to ROW. Figure 5 shows a cylclic voltammogram clearly verifying AgI formation and stripping. Due to the high electrolyte concentration (more conductivity) the peaks are actually sharper than in $0.01 \mathrm{M} \mathrm{NaOH}$.

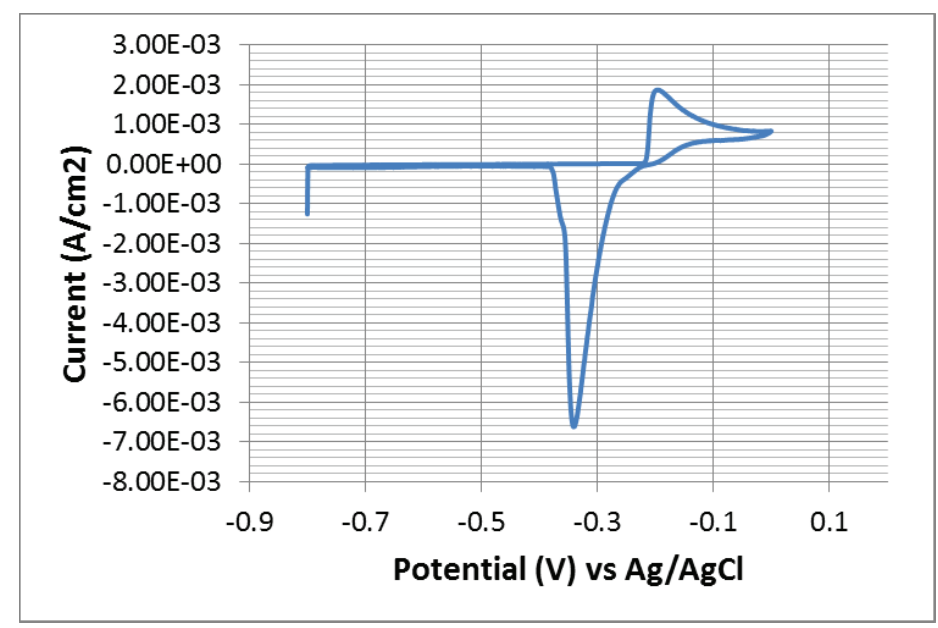

Figure 5. $\mathrm{CV}$ of $\mathrm{Ag}$ disk electrode in $1 \mathrm{mM} \mathrm{KI}$ added to Real Ocean Water with switching potential at $0 \mathrm{~V}$.

As described earlier, iodine exists primarily as $\mathrm{IO}_{3}{ }^{-}$in seawater and $\mathrm{I}^{-}$dominates only in anoxic waters. ${ }^{9}$ Previous work used iodide as the starting point in forming AgI. Thus a pretreatment is anticipated to convert these species to $\mathrm{I}^{-}$. This treatment can be performed using chemical reductants such as sodium metabisulfite $^{10}$ or sodium borohydide ${ }^{11}$. The electrochemical reduction could also be performed electrochemically although no procedure was found. We investigated the possibility of performing the conversion electrochemically.

To determine the electroactivity of $\mathrm{IO}_{3}{ }^{-}$in seawater, $10 \mathrm{mM} \mathrm{KIO}_{3}$ was added to $\mathrm{ROW}$ and $\mathrm{CV}$ performed. Cyclic voltammograms of three metal electrodes were collected as shown in Figure 5. A platinum electrode shows the most activity for $\mathrm{IO}_{3}{ }^{-}$reduction where a sharp peak is observed. The gold and silver electrodes also show a definitive peak but are less sharp and show side peaks suggesting a complex mechanism (probably not an issue for conversion). All three electrodes should be suitable for reducing $\mathrm{IO}_{3}{ }^{-}$in seawater although platinum appears to be the best choice based on more positive potential and sharper peaks suggesting faster kinetics.

9 Ibid.

${ }^{10}$ C. He, X. Hou, Y. Zhao, Z. Wang, H. Li, N. Chen, Q. Liu, L. Zhang, M. Luo, W. Liang, Y. Fan, X. Zhao, ${ }^{129}$ I Levels in Seawater Near a Nuclear Power Plant Determined by Accelerator Mass Spectrometer, Nuclear Instruments and Methods in Physics Research A 632 (2011) 152.

11 T. Freund and N. Nuenk, The Kinetics of the Reduction of Iodate Ion by Borohydride Ion in Basic Aqueous Solutions, Journal of the American Chemical Society 84 (1962) 2679. 


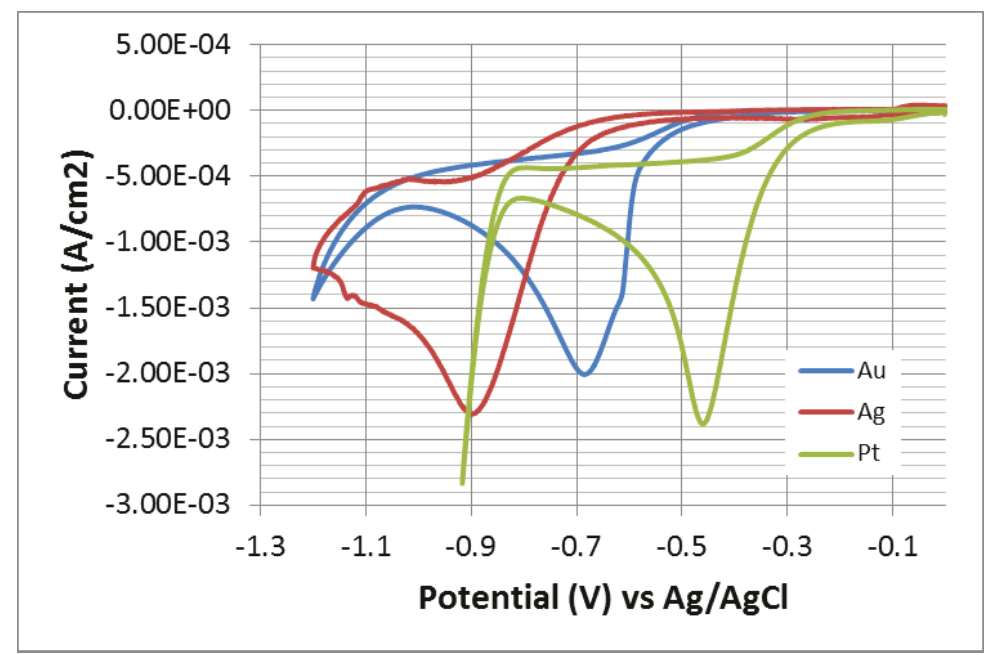

Figure 6. $\mathrm{CV}$ of $\mathrm{Ag}$ disk electrode with $\mathrm{KIO}_{3}$ added to ROW.

A number of experiments were performed to evaluate the bulk conversion of iodate to iodide. Volumes of ROW (100 mL to $1 \mathrm{~L})$ were spiked with iodate and passed through a number of different cell designs. Experiments showed that approximately $20 \%$ of the iodate was converted to iodide. A new cell design has been proposed to increase the percent conversion.

The experiments performed show that significant promise exists in using electrochemistry to process and concentrate iodine in seawater. The most promising results were for concentration of iodine rather than conversion of iodate to iodide. 


\section{CONCLUSIONS}

The goal of the project was to ensure the ongoing isotope ratio determination capability within the DOE complex is the world's best for application to nonproliferation. This report spells out the progress of Task 4, Transition of TIMS to AMS for Iodine Analysis, of the larger project New Paradigms for Isotope Ratio Mass Spectrometry: Raising the Scientific Profile and Improved Performance for AMS and TIMS. The subtasks include development of chemical extraction, determination of a detection limit for ${ }^{127} \mathrm{I}$, production of standard materials for AMS analysis quality assurance, facilitation of knowledge exchange with respect to analyzing iodine on AMS, supercritical fluid extraction of iodine for AMS analysis and electrodeposition of seawater as a direct method of preparation for iodine analysis by AMS.

A chemical extraction method was developed and demonstrated on known materials and exposed air filters. The optimized method for filter extraction is a leach with $5 \% \mathrm{TMAH}$ at a temperature of $90^{\circ} \mathrm{C}$. The iodine is transferred from the extract to the AMS cathode by electrodeposition of iodine on a silver wire. Careful control of the chemistry to maintain iodine in the correct specie was a large discovery for this work, facilitating the successful electrodepositing of samples on silver wire. For exposed air filters, the extraction requires the addition of isopropyl alcohol for charge removal from air filters. The ${ }^{127}$ I of the extracted liquid can then be determined by ICPMS. A portion of the leachate is then combined with carrier ${ }^{127} \mathrm{I}$, equilibrated through redox chemistry and electrodeposited for AMS analysis.

The determination of the ${ }^{127}$ I detection limit for a 0.5 MV AMS system using the silver wire loaded cathodes was successful. The limit is $10 \mu \mathrm{g}$ of iodine is required for a positive detection for samples with $\mathrm{a}^{129} \mathrm{I} /{ }^{127} \mathrm{I}$ isotopic ratio of $\sim 2 \times 10^{-10}$ on the AMS at ETH -Zurich. The data indicated that when the amount is less than $10 \mu \mathrm{g}$ the uncertainty in the results increases dramatically due to the small number of counts from the detection of ${ }^{129} \mathrm{I}$.

Standard materials for AMS analysis quality control were produced at four different ${ }^{129} \mathrm{I} /{ }^{127} \mathrm{I}$ levels for quality assurance of AMS operations and data. The ${ }^{129} \mathrm{I} /{ }^{127} \mathrm{I}$ ratios of the standards are $5 \times 10^{-10}, 5 \times 10^{-}$ ${ }^{11}, 5 \times 10^{-12}$ and a ${ }^{129}$ I blank. The ratio of these materials has been calibrated to NIST 3230 iodine isotopic standards.

The knowledge exchange portion of the project had great success. Data from the silver wire harvesting of iodine for cathode preparation was combined with cathodes prepared by electrodeposition data and presented in a poster at the ECAART-11 conference. An INL scientist analyzed samples prepared at the INL on the only existing 0.5 MV AMS currently analyzing iodine at ETH - Zurich. An INL scientist visited Lawrence Livermore Laboratories, two scientists spent a full week working at the ETH AMS laboratories, and two scientists participated in an international AMS conference. One oral presentation and one poster were given at the conference. The oral presentation, "Electrodeposition as an alternate method for preparation of environmental samples for iodide for analysis by AMS." was accepted and will be published in in Nuclear Instruments and Methods in Physics Research, Section B (in press); generally considered the premier journal covering accelerator mass spectrometry.

Seventeen exposed air filters were prepared by gas phase/TIMS and aqueous leaching/AMS to compare the methods directly. Ten samples from the exposed filters were prepared and shipped to ETH for cross comparison of the INL AMS with a world leading AMS laboratory.

Supercritical fluid extraction was evaluated as an alternate method to extract the iodine species from an air filter sample. Electrodeposition of iodine species from seawater was very successful and will result in a publication. 
The goal of the project is to ensure the ongoing isotope ratio determination capability within the DOE complex is the world's best for application to nonproliferation. This report spells out the progress of Task 4, Transition of TIMS to AMS for Iodine Analysis, of the larger project New Paradigms for Isotope Ratio Mass Spectrometry: Raising the Scientific Profile and Improved Performance for AMS and TIMS. FY15 was a very productive year; the INL AMS was delivered and turned over in February 2015. Since then, INL scientists have been successfully vetting the capabilities and accomplishing their own measurements that agree well with the leading laboratories of the world for iodine analysis by AMS. Initially, all AMS data was obtained on other laboratories instruments, but during the last six months data for this project has come from INL's AMS. The expedited stand up of this capability at INL has been directly due to the accomplishments and preparation enabled by this project. 